\title{
Precedence-effect-induced enhancement of prepulse inhibition in socially reared but not isolation-reared rats
}

\author{
Yi Du, Jingyu Li, XiHong Wu, AND LiAng Li \\ Peking University, Beijing, China
}

\begin{abstract}
Attention to a prepulse presented shortly before a startling stimulus enhances prepulse inhibition (PPI) of startle in normal people, but not in schizophrenics. Fear conditioning for the prepulse enhances PPI in socially reared, but not isolation-reared, rats. In humans, selective attention to acoustic signals against masking can be facilitated by precedence-effect-induced perceived spatial separation between the signal and the masker. This study investigated whether perceived spatial separation between a prepulse and a noise masker enhances PPI in socially reared rats and isolation-reared rats. The results show that both PPI and conditioning-induced PPI enhancement were larger in socially reared rats than in isolation-reared rats. More important, in socially reared, but not isolation-reared, rats, a further PPI enhancement was induced by precedence-effect-induced perceived separation between a prepulse and a masker only after the prepulse became fear conditioned. Thus, perceived separation facilitates normal rats' attention to a conditioned prepulse and enhances PPI. Isolation rearing impairs rats' ability to attend to ecologically significant acoustic events.
\end{abstract}

Prepulse inhibition (PPI) is the normal reduction of the amplitude of the startle reflex in response to an intense startling stimulus (pulse) when the startling stimulus is preceded a short time before by a weaker, nonstartling sensory stimulus (prepulse) (Buckland, Buckland, Jamieson, \& Ison, 1969; Pickney, 1976; for reviews, see Hoffman \& Ison, 1980; Ison \& Hoffman, 1983; L. Li \& Yue, 2002). Graham (1975) proposed a protection-of-processing theory for justifying the function of PPI that dampens the disruptive influence from startle. Since consequences of PPI include the reduction of behavioral responses to disruptive stimuli by regulating the motor system and/or the premotor system, PPI has been generally recognized as a simple operational measure of sensorimotor gating. The magnitude of PPI has also been widely used as a measure of the salience of the prepulse stimulus in rodents (Barsz, Ison, Snell, \& Walton, 2002; Carlson \& Willott, 1996; J. Huang et al., 2007; Ison, Agrawal, Pak, \& Vaughn, 1998; Ison \& Bowen, 2000; Leitner \& Girten, 1997; L. Li, Korngut, Frost, \& Beninger, 1998; Turner, Brozoski, Bauer, Parrish, \& Myers, 2006; Young \& Fechter, 1983; Zou, Huang, Wu, $\& \mathrm{Li}, 2007)$.

Although the pathway mediating PPI is located in the brainstem (for a review, see L. Li \& Yue, 2002), PPI can be modulated by higher order central processing. In humans, selective attention to the prepulse enhances PPI (e.g., Filion \& Poje, 2003; Heekeren, Meincke, Geyer, \& Gouzoulis-Mayfrank, 2004; Schell, Wynn, Dawson, Sinaii, \& Niebala, 2000; Thorne, Dawsona, \& Schell,
2005), and PPI is more pronounced when the prepulse is emotionally salient than when it is a neutral stimulus (Bradley, Codispoti, \& Lang, 2006; Bradley, Cuthbert, \& Lang, 1993). In rats with normal rearing, when the prepulse becomes fear conditioned (J. Huang et al., 2007; N. X. Li et al., 2008; Zou et al., 2007) or fear-extinction conditioned (Röskam \& Koch, 2006), PPI is markedly enhanced, suggesting that the facilitation of rats' selective attention to the prepulse and/or the spatial location of the prepulse can be built up when the prepulse becomes ecologically significant. To further confirm the effects of selective attention to a prepulse on PPI in rats, new testing paradigms, in which selective attention is clearly involved, need to be established.

In a noisy, reverberant environment, listeners receive not only sound waves that directly emanate from various sources, but also reflections from surfaces at various locations. In such an environment, to perceptually segregate a target signal from other disruptive stimuli, perceptual integration of correlated sound waves is critical. Only when the target stimulus is not highly correlated with disruptive stimuli does the brain have a better chance to segregate the target percept from disruptor percepts. Otherwise, the auditory scene will be cluttered and confusing. Humans with normal hearing have the ability to perceptually integrate correlated sound waves. When the time interval between the direct wave coming from the source and a reflected wave of the source is sufficiently short, attributes of the delayed reflection are perceptually captured by the direct 
wave (L. Li, Qi, He, Alain, \& Schneider, 2005), leading to a single fused image whose point of origin is perceived to be around the location of the leading source. This phenomenon is called the precedence effect (Blauert, 1997; L. Li \& Yue, 2002; Litovsky, Colburn, Yost, \& Guzman, 1999; Wallach, Newman, \& Rosenzweig, 1949). Since a source is usually more correlated with its time-delayed reflections and less correlated (or uncorrelated) with other sources, the perceptual integration associated with the precedence effect facilitates perceived spatial segregation of signals from various sources.

In humans, the importance of perceptual fusion of correlated sound waves for recognizing speech signals has been experimentally demonstrated (e.g., Freyman, Helfer, McCall, \& Clifton, 1999; Y. Huang et al., 2008; L. Li, Daneman, Qi, \& Schneider, 2004; Rakerd, Aaronson, \& Hartmann, 2006; Wu et al., 2005). For example, on the basis of the principle of the precedence effect, when both the target speech and the masker (either speech masker or noise masker) are presented by a loudspeaker to the listener's left and by another loudspeaker to the listener's right, the perceived location of the target and that of the masker can be manipulated by changing the delay between the two loudspeakers for the target signal and the masker signal (L. Li et al., 2004). Recognizing target speech is significantly better under the condition of perceived target-masker spatial separation than under the condition of perceived target-masker colocation, even though neither the masker energy at each ear nor the masker-image compactness/diffusiveness is substantially changed. The reduction of masking is caused by improved selective attention to the target.

It has been well documented that the precedence effect can be demonstrated in behaving laboratory animals, including rats (e.g., Hoeffding \& Harrison, 1979; Kelly, 1974), cats (e.g., Cranford \& Oberholtzer, 1976; Dent, Tollin, \& Yin, 2004), and birds (e.g., Dent \& Dooling, 2004; Spitzer \& Takahashi, 2006). However, it has not been shown in the literature whether, in laboratory animals, precedenceinduced perceived spatial separation unmasks target sounds. The purpose of this study was to investigate whether the precedence-induced perceived spatial separation between a prepulse and a masker can facilitate PPI.

Schizophrenic patients usually suffer from impaired sensory gating that filters out distracting stimuli to ensure useful information processing (for reviews, see Braff, Geyer, \& Swerdlow, 2001; Geyer, Krebs-Thomson, Braff, \& Swerdlow, 2001). PPI deficits occur in schizophrenic patients and schizotypal personality disordered subjects (e.g., Braff et al., 1978; Braff, Swerdlow, \& Geyer, 1999; Dawson, Schell, Hazlett, Nuechterlein, \& Filion, 2000; Kumari, Soni, Mathew, \& Sharma, 2000; Swerdlow et al., 2006). The neurodevelopmental hypothesis of schizophrenia emphasizes the substantial influence of early-life environmental factors upon the processes of brain maturation (McGrath, Feron, Burne, Mackay-Sim, \& Eyles, 2003; Meyer, Feldon, Schedlowskib, \& Yee, 2005; van den Buuse, Garner, \& Koch, 2003; Weinberger, 1987). For establishing an animal developmental model for studying schizophrenia, one of the early-life manipulations in labo- ratory rats is isolation rearing after weaning (21 days after birth; for a review, see Weiss \& Feldon, 2001). In rats, either early maternal separation or social isolation induces PPI deficits (e.g., Cilia, Hatcher, \& Reavill, 2005; N. X. Li et al., 2008; van den Buuse et al., 2003). In schizophrenic patients, attentional modulation of PPI is impaired (Dawson, Hazlett, Filion, Nuechterlein, \& Schell, 1993; Hazlett et al., 2003; Hazlett et al., 2007); in rats with isolation rearing, the conditional enhancement of PPI is impaired (N. X. Li et al., 2008). Moreover, as compared with normal controls and anxiety patients, schizophrenic patients perform much worse with noise in forward-masking and backward-masking tasks (Kallstrand, Montnémery, Nielzn, \& Olsson, 2002), suggesting that the perceptual salience of target signals is more vulnerable to noise masking in schizophrenics. Recognition of a target sound against a noisy background needs selective attention to the target, and, as was mentioned above, perceived spatial separation between a target sound and a masker facilitates listeners' selective attention to the target even when the signal-to-noise ratio (SNR) is not substantially changed (Freyman et al., 1999; L. Li et al., 2004). It is important to know whether schizophrenics are less able to perceptually segregate the target sound (such as a prepulse) from irrelevant sounds.

This study was performed to investigate whether perceptual separation between a prepulse and a masker affects PPI in rats before and after the prepulse becomes fear conditioned. Moreover, to further advance the animal model for investigating both the neural bases and cognitive features of schizophrenia, this study also investigated whether isolation rearing affects the effects of perceived spatial separation.

One audible component of the rats' vocal response to tail pain has been called chatter, characterized by a fundamental frequency $(f 0)$ plus several harmonics (Jourdan, Ardid, Chapuy, Eschalier, \& Le Bars, 1995). Frequencyfollowing responses are sustained neural potentials based on precisely phase-locked neural activities elicited by low- to medium-frequency periodical sound waveforms (Marsh, Worden, \& Smith, 1970). We recently used the vowel-like chatter with an $f 0$ of $2.1 \mathrm{kHz}$ as an acoustic stimulus and found that frequency-following responses to the $f 0$ can be reliably recorded in anesthetized rats' amygdala and auditory midbrain inferior colliculus (Du, Huang, Wu, Galbraith, \& Li, 2007). We plan to use this neurophysiological recording method to trace the central representation of the prepulse signal during the measurement of acoustic startle responses in awake rats before and after the prepulse is fear conditioned. For the purpose of linking the present behavioral study with our future combined behavioral and neurophysiological studies, a 150 -msec section of the chatter was used as the prepulse stimulus in this study.

\section{METHOD}

\section{Subjects}

Thirty-two male Sprague-Dawley rats (Vital-River Experimental Animals Technology Ltd., Beijing) at the age of weaning 
(21 days old) were randomly assigned to a socially reared group (16 rats) and an isolation-reared group (16 rats). Each group was further randomly divided into an auditory fear-conditioning subgroup (8 rats) and a conditioning-control subgroup (8 rats). For isolation-reared rats, each individual was housed in a single transparent plastic cage $(48 \times 30 \times 18 \mathrm{~cm})$. For socially reared rats, 3 individuals were housed in a cage with the same dimensions. All the rats were kept in the same room for 8 weeks before testing, under a temperature of $24 \pm 2^{\circ} \mathrm{C}$ and a 12-h light:dark cycle, with food and water freely available. The rearing procedures have been described in detail elsewhere (N. X. Li et al., 2008; N. X. Li, Wu, \& Li, 2007).

\section{Startle Response Measurement and the Prepulse}

The rat's whole-body startle reflex, which was induced by a 10 -msec broadband noise burst (100 dB SPL) delivered by a loudspeaker above the rat's head, was measured by a custom-made electrical scale (National Key Laboratory on Machine Perception, Peking University) in a soundproof chamber (for details, see J. Huang et al., 2007; N. X. Li et al., 2008; Zou et al., 2007). A 150-msec section of the rat's call in response to tail-clamping pain was delivered by each of the two additional loudspeakers (which were placed horizontally in the frontal field, with a $100^{\circ}$ separation angle) as the prepulse.

The procedure for producing the prepulse stimulus was the following. A train of tail-pain chatter (Figure 1A) was recorded from 1 rat in response to tail-clamping pain in a soundproof chamber and was digitized at a $44.1-\mathrm{kHz}$ sampling rate and 16-bit resolution. A fragment of 150 -msec chatter without any amplitude modulation or frequency modulation was isolated from a single chatter burst (Figure 1B), was tapered with 5-msec linear onset/offset ramps (Figure $1 \mathrm{C}$ ), and was used as the prepulse stimulus in this study. The spectrum of the prepulse stimulus showed an $f 0$ at $2.1 \mathrm{kHz}$ and two harmonics at $4.2 \mathrm{kHz}(\mathrm{h} 2)$ and $6.3 \mathrm{kHz}$ (h3) (Figure 1D).

\section{Procedure}

For the first 3 successive days, the rat was placed into the restraining cage, where it was held during the measurement of the startle reflex (Zou et al., 2007), and was exposed to a broadband noise $(0-10 \mathrm{kHz}, 55 \mathrm{~dB}$ SPL), which was continuously presented via each of the two horizontal loudspeakers, for $30 \mathrm{~min}$ each day. During the restraining period, neither the prepulse nor the startling noise was presented. This procedure's purpose was to adapt the rat to the cage and testing chamber.

On the 4th day, premanipulation PPI was measured. The rat was placed in the cage for $5 \mathrm{~min}$, receiving 10 presentations of the startling stimulus without prepulse presentation. The interval between the startling stimuli was about $30 \mathrm{sec}$ (varying from 25 to $35 \mathrm{sec}$ ). Then three testing sessions were conducted.

In Session 1 , the prepulse ( $55 \mathrm{~dB}$ SPL) was presented in quiet from each of the two horizontal loudspeakers, with the onset delay between the two loudspeakers being either $+1 \mathrm{msec}$ (left leading) or $-1 \mathrm{msec}$ (right leading). Due to the precedence effect, the attributes of the prepulse from the lagging loudspeaker were perceptually captured by those from the leading loudspeaker (L. Li et al., 2005), and a single fused prepulse image was perceived as coming from the leading loudspeaker. The 1-msec intersound delay was within the range for producing perceptual fusion in behaving rats (Kelly, 1974). Fifty milliseconds after the offset of the prepulse, the startling noise burst was presented via the top loudspeaker. Then a new trial started about $30 \mathrm{sec}$ (varying from 25 to $35 \mathrm{sec}$ ) after the offset of the prepulse. Ten trials with the prepulse and 10 trials without the prepulse were presented in a random manner.

In Sessions 2 and 3, the prepulse was presented from each of the two horizontal loudspeakers, with the prepulse onset delay between the two loudspeakers being either +1 msec (left leading) or $-1 \mathrm{msec}$ (right leading). In addition to the prepulse, a broadband noise (0-10 kHz, $55 \mathrm{~dB}$ SPL) was continuously delivered from each of the two horizontal loudspeakers throughout the whole session

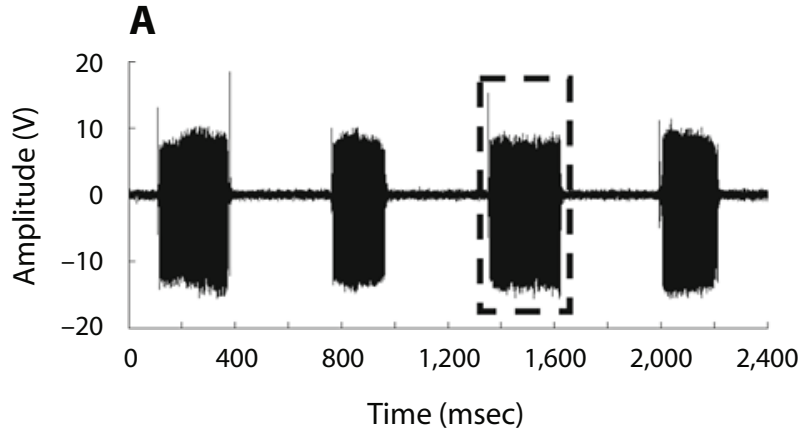

B
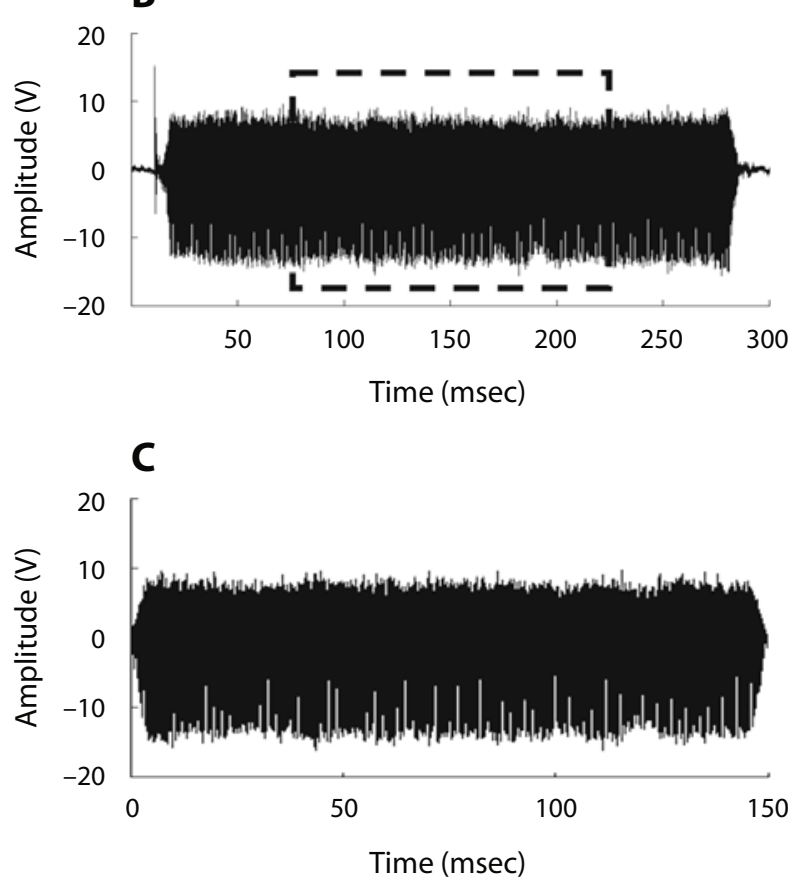

D

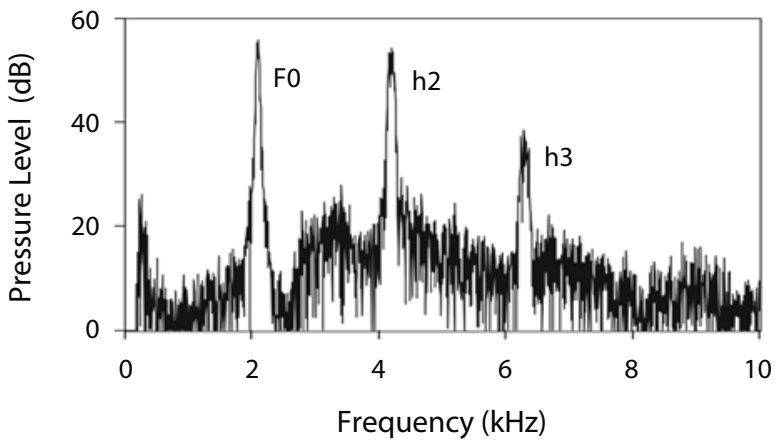

Figure 1. Waveform and spectrums of the prepulse. (A) A train of ongoing tail-pain chatters, emitted by a rat in response to tailclamping pain, was recorded in a soundproof chamber and was digitized at a 44.1-kHz sampling rate and 16-bit resolution. An individual charter burst (in the dashed box) was selected. (B) A 150-msec stimulus fragment was further isolated in the middle of the selected chatter burst. (C) A 5-msec linear ramp was added in the onset and offset of the isolated stimulus fragment, and then the fragment became the prepulse stimulus. (D) The spectrum of the prepulse had a fundamental frequency $(F 0)$ at $2.1 \mathrm{kHz}$ and two harmonics at $4.2 \mathrm{kHz}(\mathrm{h} 2)$ and $6.3 \mathrm{kHz}(\mathrm{h} 3)$. 
as the masker. The onset of the noise presented from the left loudspeaker led that from the right loudspeaker by $1 \mathrm{msec}(+1 \mathrm{msec})$ in one session and lagged behind that from the right loudspeaker by $1 \mathrm{msec}(-1 \mathrm{msec})$ in the other session, leading to a single fused noise image being perceived at the left loudspeaker in one session and at the right loudspeaker in the other session, due to the precedence effect. The level of the prepulse was adjusted to produce two SNRs, 4 and $-4 \mathrm{~dB}$, in each of the two sessions. Thus, each of the two perceived spatial relationships between the target and the masker (perceived colocation and perceived spatial separation) was induced in each of the last two sessions (Sessions 2 and 3). In each of the last two sessions, 10 trials were assigned to each of the four $(2 \times 2) \mathrm{SNR} /$ spatial relationship combinations, and 10 trials were assigned to the no-prepulse condition.

On the 5th day, all the subgroups underwent the manipulation of fear conditioning or the manipulation of conditioning control. The acoustic conditioned stimulus (CS) was the prepulse delivered by each of the two horizontal loudspeakers, with a left/right-leading balance. On the basis of previous studies (Sikes \& Vogt, 1992; Villanueva, Bing, Bouhassira, \& Le Bars, 1989), the unconditioned stimulus (US) was a 6-mA rectangular-pulse (duration $=3 \mathrm{msec}$ ) footshock using Grass S-88 stimulator (Grass, Quincy, MA). The short duration of footshock applied in this and our previous studies (J. Huang et al., 2007; N. X. Li et al., 2008; Zou et al., 2007) removed any potential effects of escaping movement, which might occur if the duration of the footshock was long (e.g., $500 \mathrm{msec}$ ).

For the two fear-conditioning subgroups, 20 precisely combined pairs of the CS and US (the US started $3 \mathrm{msec}$ before the CS ending and coterminated with the CS) were presented every $30 \mathrm{sec}$. For the two conditioning-control subgroups, the pairing of the CS and US was temporally randomized and repeated 20 times.

On the 6 th day ( $24 \mathrm{~h}$ after the manipulation of fear conditioning or the manipulation of conditioning control), PPI was measured, using the same three-session procedure.

On the 7th day, the two fear-conditioning subgroups underwent the manipulation of auditory fear extinction, during which the CS was presented every $30 \mathrm{sec}$, without pairing with the US, for 60 times ( 3 sessions with 20 presentations in each and 10-min intersession intervals).

On the 8th day (24 $\mathrm{h}$ after the extinction manipulation), PPI in rats with the extinction manipulation was measured, using the same three-session procedure.

\section{Data Analyses}

The amount of PPI was calculated with the following generally used formula:

PPI $(\%)=$ (amplitude to startling sound alone - amplitude to startling sound preceded by prepulse) / (amplitude to startling sound alone) $\times 100 \%$.

The amount of PPI gain due to perceived spatial separation was calculated using the following formula:

PPI Gain by PSS $(\%)=$

$$
\frac{\frac{\mathrm{PPI}_{-4 / \text { Sep }}-\mathrm{PPI}_{-4 / \text { Nosep }}}{\mathrm{PPI}_{-4 / \text { Nosep }}}+\frac{\mathrm{PPI}_{4 / \text { Sep }}-\mathrm{PPI}_{4 / \text { Nosep }}}{\mathrm{PPI}_{4 / \text { Nosep }}}}{2} \times 100 \% \text {, }
$$

where, PSS represents perceived spatial separation between the prepulse and noise masker; -4 and 4 represent the SNR of -4 and $+4 \mathrm{~dB}$, respectively; and Sep and Nosep represents the condition with perceived spatial separation and the condition without perceived spatial separation, respectively.

\section{Statistical Analyses}

ANOVAs were performed and were followed by Bonferroni post hoc tests, using SPSS 11.5 software (for details, see the Results section). The null-hypothesis rejection level was set at .05.
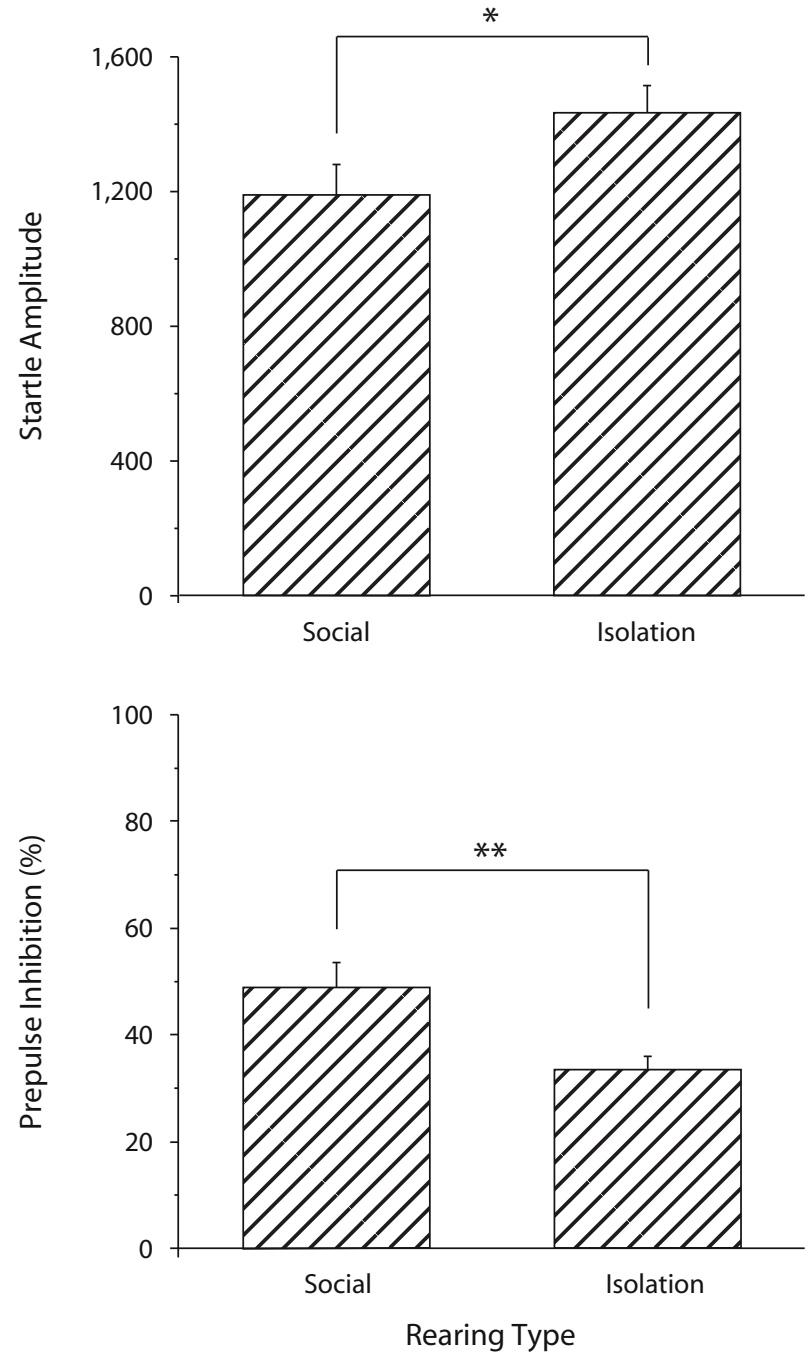

Figure 2. Upper panel: The group-mean magnitudes of startle before manipulations in socially reared rats and in isolationreared rats. The startle magnitude in isolation-reared rats was significantly higher than that in socially reared rats. Lower panel: The group-mean magnitudes of prepulse inhibition (PPI) before manipulations in socially reared rats and in isolationreared rats. The PPI magnitude in isolation-reared rats was significantly lower than that in socially reared rats. Error bars represent the standard errors of the means. ${ }^{*} p<.05 .{ }^{* *} p<$ .01 , by one-way ANOVA.

\section{RESULTS}

\section{Effects of Social Isolation on the Startle Reflex and PPI Before Fear Conditioning}

The upper panel of Figure 2 shows the group-mean amplitudes of the startle reflex in socially reared rats and in isolation-reared rats before the manipulation of fear conditioning or the manipulation of conditioning control. The startle amplitude in isolation-reared rats appears to have been larger than that in socially reared rats. A one-way ANOVA confirmed that startle amplitude in isolationreared rats was significantly larger than that in socially 


\section{Socially Reared}

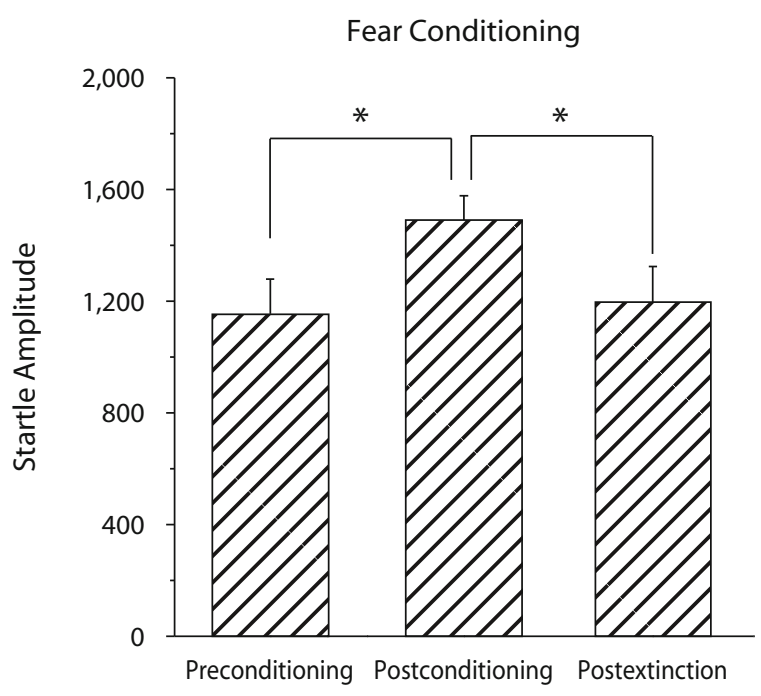

Conditioning Control

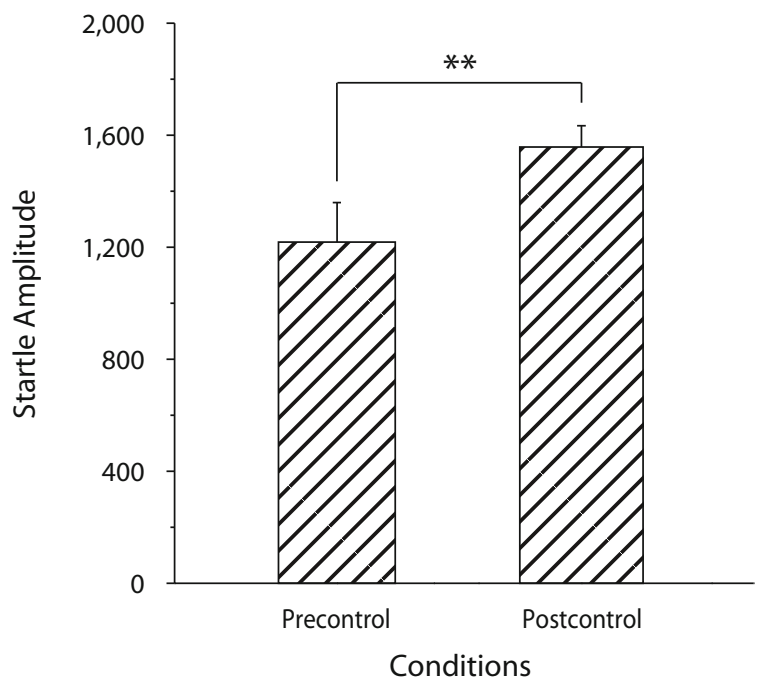

Isolation Reared

Fear Conditioning

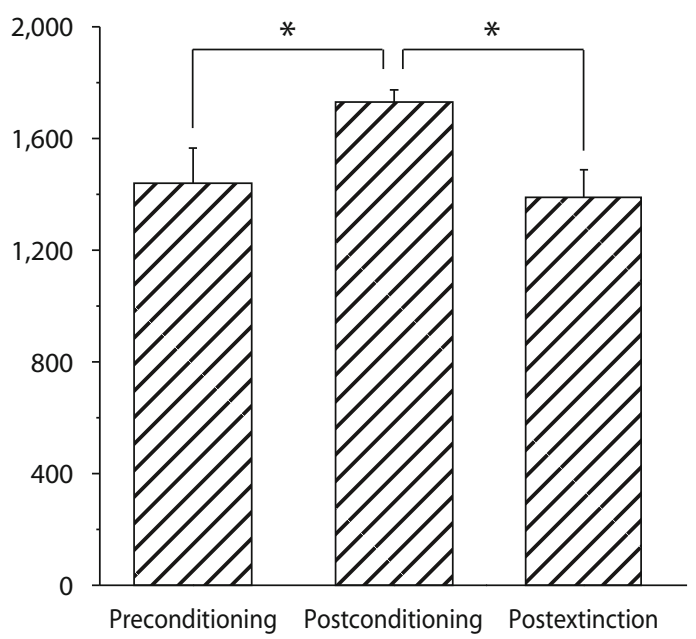

Conditioning Control

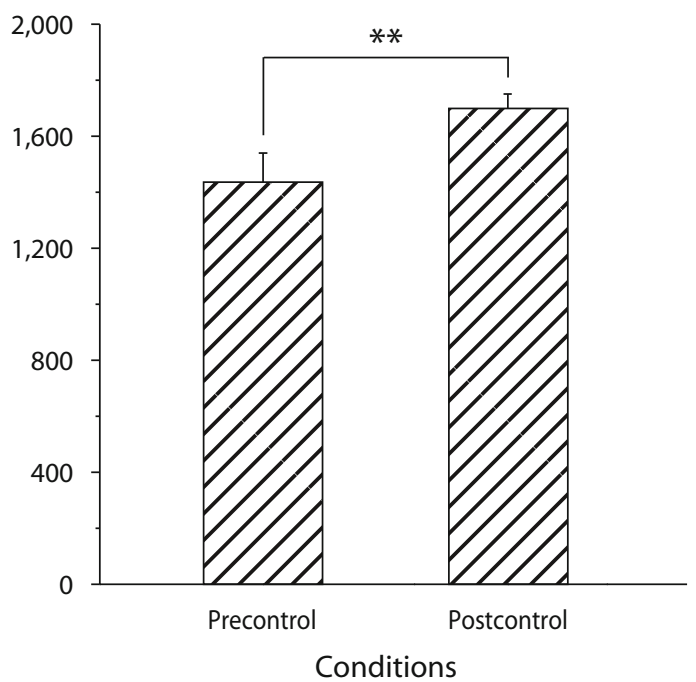

Figure 3. Startle amplitudes under no-masking conditions before and after different manipulations for each of the four subgroups. Note that both the manipulation of fear conditioning and the manipulation of conditioning control caused a marked enhancement of startle in both socially reared rats and isolation-reared rats. Also, startle amplitudes after the extinction manipulation decreased to the preconditioning level in rats with the manipulation of fear conditioning. Error bars represent the standard errors of the means. ${ }^{*} p<.05$. ${ }^{* *} p<.01$, by one-way ANOVA and Bonferroni post hoc tests.

reared rats $[F(1,30)=4.2, p<.05]$. Additional one-way ANOVAs showed that before manipulations, there was no difference in startle amplitude either between the two socially reared subgroups or between the two isolationreared subgroups $(p>.05)$.

The lower panel of Figure 2 shows that group-mean PPI in socially reared rats was larger than that in isolationreared rats before the manipulation of fear conditioning or the manipulation of conditioning control. A one-way ANOVA indicated that the difference in PPI between socially reared rats and isolation-reared rats was significant
$[F(1,30)=8.4, p<.01]$. Additional one-way ANOVAs showed that before manipulations, there was no significant difference in PPI either between the two socially reared subgroups or between the two isolation-reared subgroups $(p>.05)$.

\section{Effects of Auditory Fear Conditioning or Conditioning-Control Manipulation on Startle Reflex and PPI}

Figure 3 shows the startle amplitudes for each of the four subgroups before and after manipulations when the 


\section{Socially Reared}

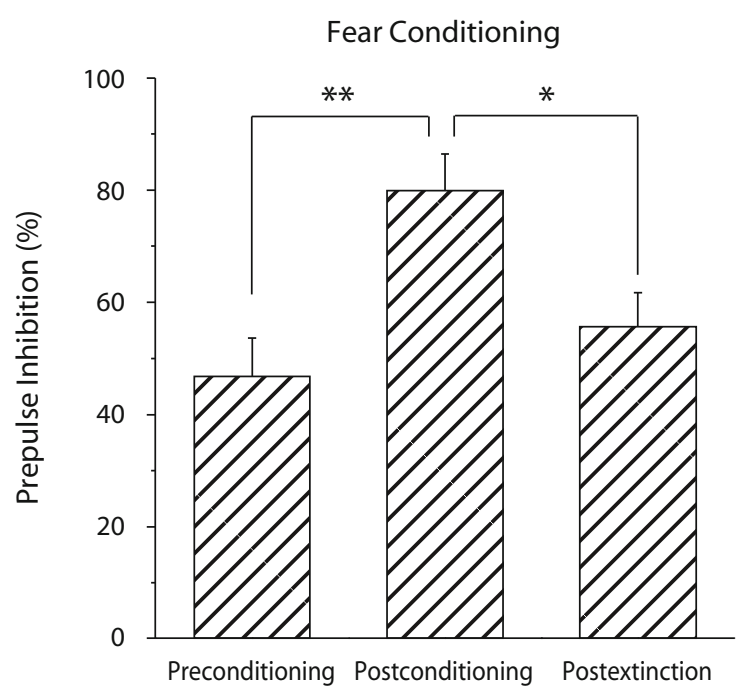

Conditioning Control

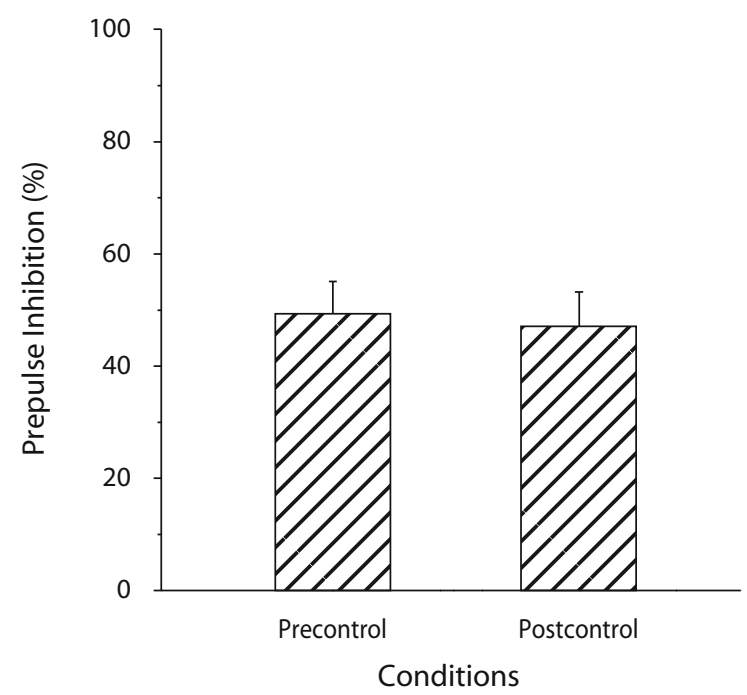

Isolation Reared

Fear Conditioning

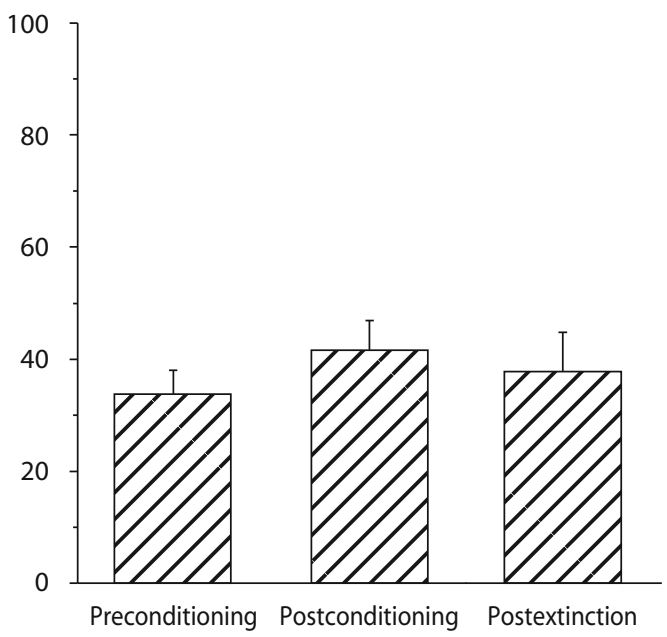

Conditioning Control

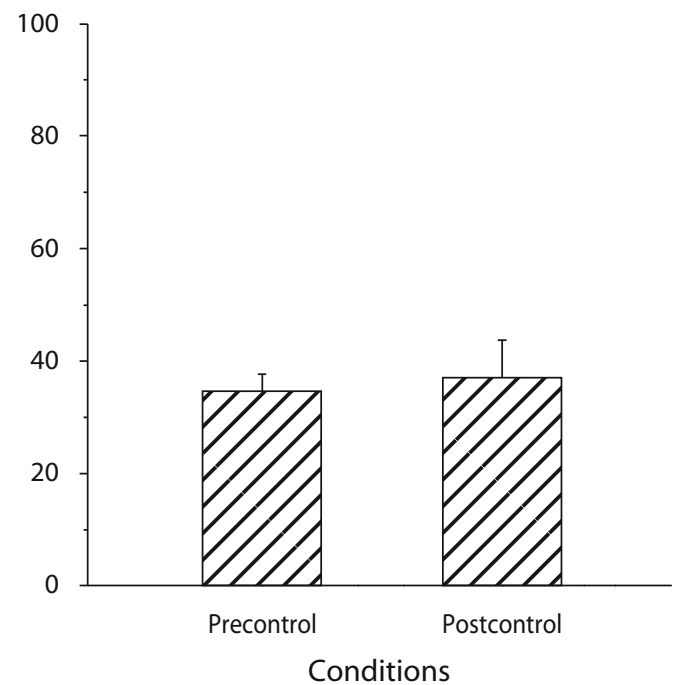

Figure 4. Prepulse inhibition (PPI) under no-masking conditions before and after different manipulations in each of the four subgroups. Note that the manipulation of fear conditioning, but not the manipulation of conditioning control, caused a marked enhancement in PPI in socially reared rats, but a much weaker enhancement in isolation-reared rats. Also, PPI after the extinction manipulation decreased to the preconditioning level in socially reared rats with the manipulation of fear conditioning. Error bars represent the standard errors of the means. $\quad{ }^{*} p<.05 . \quad{ }^{* *} p<.01$, by one-way ANOVA and Bonferroni post hoc tests.

noise masker was not presented. Generally, either the manipulation of fear conditioning or the manipulation of conditioning control enhanced the baseline startle.

A 2 (rearing type: social, isolation) $\times 2$ (manipulation type: fear conditioning, conditioning control) $\times 2$ (testing time: preconditioning/control, post-fear-conditioning/ control) three-way ANOVA showed that the main effects of testing time $[F(1,56)=19.254, p<.001]$ and rearing type $[F(1,56)=9.423, p<.01]$ were significant but the main effect of manipulation type was not significant $(p>$ $.05)$ and all the interactions were not significant $(p>.05)$.
Thus, there were no differences between the manipulation of fear conditioning and the manipulation of conditioning control in causing the increase of startle amplitude, and the startle amplitude in isolation-reared rats was generally larger than that in socially reared rats.

To examine the effect of extinction for the two subgroups with the manipulation of fear conditioning (the two upper panels of Figure 3), a 2 (rearing type) $\times 3$ (testing time: preconditioning, postconditioning, postextinction) twoway ANOVA showed that the main effects of rearing type $[F(1,42)=7.4, p<.01]$ and testing time on startle am- 
plitude $[F(1,42)=6.0, p<.01]$ were significant but the interaction between rearing type and testing time was not significant $(p>.05)$. Bonferroni post hoc tests showed significant differences between preconditioning and postconditioning testing $(p<.05)$, between postconditioning and postextinction testing $(p<.05)$, but not between preconditioning and postextinction testing $(p>.05)$. Thus, extinction significantly reduced the startle amplitude in both socially reared and isolation-reared rats.

These results indicate that isolation-reared rats exhibited larger startle than did socially reared rats; both precisely and randomly temporal combinations of the prepulse with footshock significantly enhanced startle in both socially reared and isolation-reared rats, and for rats with the manipulation of fear conditioning, the startle enhancement was substantially reduced following the extinction manipulation.

Figure 4 shows PPI for each of the four subgroups before and after different manipulations when the noise masker was not presented. Clearly, a marked increase in PPI occurred only in the socially reared subgroup with fear conditioning.

A 2 (rearing type) $\times 2$ (manipulation type) $\times 2$ (testing time: preconditioning/control, postconditioning/control) three-way ANOVA showed that the main effects of rearing type $[F(1,56)=23.646, p<.001]$, manipulation type $[F(1,56)=4.321, p<.05]$, and testing time $[F(1,56)=$ $5.354, p<.05]$; the three-factor interaction $[F(1,56)=$ $4.675, p<.05]$; and the interaction between manipulation type and testing time $[F(1,56)=5.643, p<.05]$ were significant, but that neither the interaction between rearing type and testing time nor the interaction between rearing type and manipulation type was significant $(p>.05)$.

For the two subgroups with the manipulation of fear conditioning (the two upper panels of Figure 4), a 2 (rearing type) $\times 3$ (testing time) two-way ANOVA showed that the main effects of rearing type $[F(1,42)=24.6$, $p<.001]$ and testing time $[F(1,42)=5.3, p<.01]$ and the interaction between rearing type and testing time $[F(1,42)=3.3, p<.05]$ were significant. For socially reared rats receiving the manipulation of fear conditioning, a one-way ANOVA showed that the effect of testing time was significant $[F(2,21)=7.0, p<.01]$, and Bonferroni post hoc tests showed significant differences between preconditioning and postconditioning testing $(p<.01)$ and between postconditioning and postextinction testing $(p<.05)$ but not between preconditioning and postextinction testing $(p>.05)$. For isolation-reared rats receiving the manipulation of fear conditioning, a one-way ANOVA showed that the effect of testing time was not significant $(p>.05)$.

For the two subgroups with the manipulation of conditioning control (the two lower panels of Figure 4), a 2 (rearing type) $\times 2$ (testing time) two-way ANOVA indicated that the main effect of rearing type on PPI was significant $[F(1,28)=4.8, p<.05]$, but neither the main effect of testing time nor the interaction between rearing type and testing time was significant $(p>.05)$.

These results indicate that the manipulation of fear conditioning, but not the manipulation of conditioning con- trol, significantly enhanced PPI in socially reared rats, but not in isolation-reared rats. When there was no masking noise, the fear-conditioning-induced PPI enhancement in socially reared rats was substantially reduced by the extinction manipulation.

\section{Effects of Perceived Spatial Separation on PPI}

Figure 5 shows PPI obtained under noise-masking conditions for the two subgroups receiving the manipulation of fear conditioning. All three factors (SNR, manipulation, and perceived location) appear to have affected PPI for the two subgroups. However, the manipulation effect and the perceived-location effect appear to have been much weaker in the isolation-reared subgroup.

For the socially reared rats receiving the manipulation of fear conditioning (the three upper panels of Figure 5), a 2 (SNR: $-4 \mathrm{~dB}, 4 \mathrm{~dB}) \times 2$ (perceived location: no separation, separation) $\times 3$ (testing time: preconditioning, postconditioning, postextinction) repeated measures ANOVA showed that all the three main effects were significant [SNR, $F(1,7)=23.4, p<.01$; perceived location, $F(1,7)=34.0, p<.01$; testing time, $F(2,6)=9.4, p<$ $.05]$, the interaction between testing time and perceived location was significant $[F(2,6)=108.4, p<.001]$, but all the other interactions were not significant $(p \mathrm{~s}>$ .05 ). Separate $2(\mathrm{SNR}) \times 2$ (location) repeated measures ANOVAs showed that for the socially reared rats, the main effect of perceived location on PPI was not significant before the fear-conditioning manipulation $(p>.05)$ but became significant after the fear-conditioning manipulation $[F(1,7)=63.1, p<.001]$ and even after the extinction manipulation $[F(1,7)=16.8, p<.01]$. The main effect of SNR was significant $(p<.05)$, but the interaction between SNR and perceived location was not significant $(p>.05)$, at each of the three testing stages.

For isolation-reared rats receiving the manipulation of fear conditioning (the three lower panels of Figure 5), a $2(\mathrm{SNR}) \times 2$ (location) $\times 3$ (testing time) repeated measures ANOVA showed that only the main effect of SNR was significant $[F(1,7)=22.8, p<.01]$.

Figure 6 shows PPI obtained under noise-masking conditions for two subgroups with the manipulation of conditioning control. For socially reared rats and isolationreared rats, separate $2(\mathrm{SNR}) \times 2$ (perceived location) $\times$ 2 (testing time) repeated measures ANOVAs showed that only the main effect of SNR was significant [socially reared, $F(1,7)=29.1, p<.01$; isolation reared $F(1,7)=$ $31.1, p<.01]$.

These results indicate that relative to perceived colocation of the prepulse and masker, perceived spatial separation between the prepulse and masker enhanced PPI only in socially reared rats after the manipulation of fear conditioning had been conducted and even after the extinction manipulation had been conducted.

\section{PPI Gains Induced by Perceived Spatial Separation}

The PPI gain is used to indicate the PPI difference between the condition of perceived spatial separation and that of perceived colocation of the prepulse and masker. 
Preconditioning
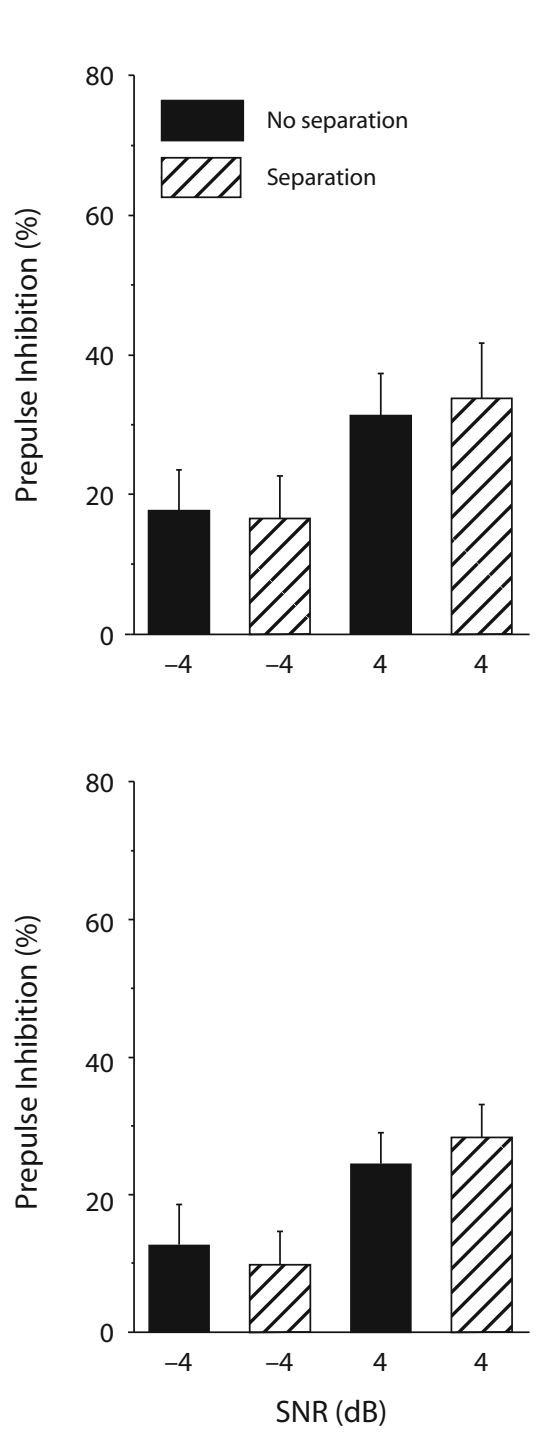

\section{Postconditioning}

Socially Reared

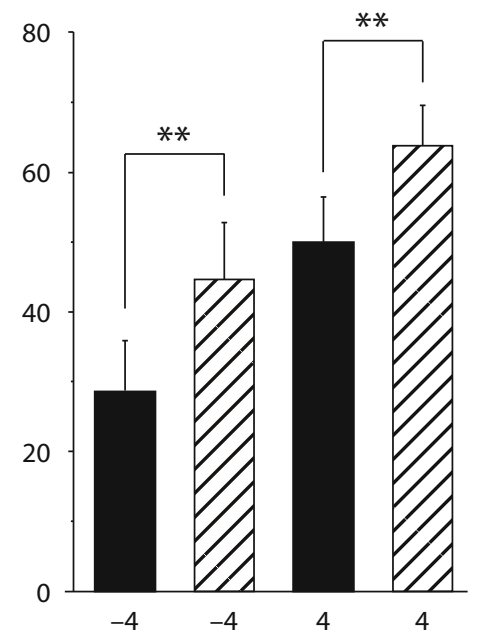

Isolation Reared

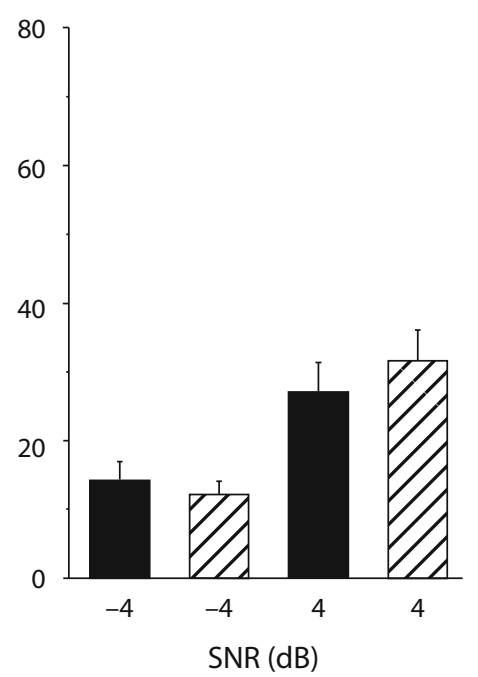

Postextinction
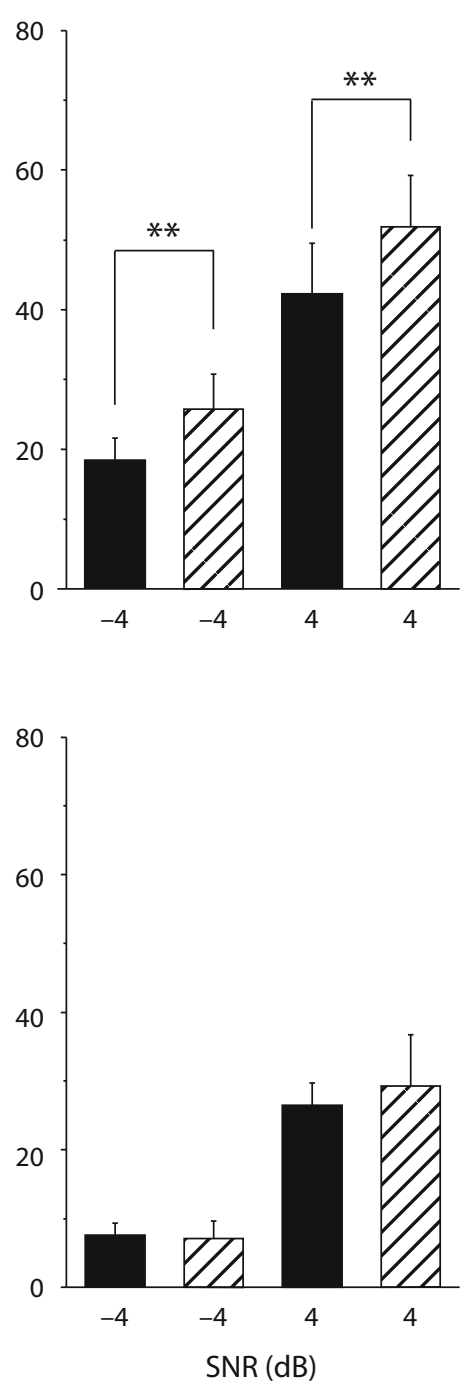

Figure 5. Prepulse inhibition (PPI) under noise-masking conditions before and after the manipulation of fear conditioning and the extinction manipulation, when the signal-to-noise ratio (SNR) was either -4 or $+4 \mathrm{~dB}$ and the prepulse and masker were either perceptually separated (diagonal bars) or perceptually colocated (black bars) for the two subgroups receiving the manipulation of fear conditioning. Note that perceived spatial separation had no effect on PPI before the manipulation of fear conditioning in both socially reared and isolation-reared rats, but significantly enhanced PPI after the manipulation of fear conditioning only in socially reared rats. Error bars represent the standard errors of the means. ${ }^{* *} p<.01$, by ANOVA.

The PPI gains for each of the four subgroups before and after a certain manipulation are shown in Figure 7.

For socially reared rats with the manipulation of fear conditioning, a one-way ANOVA showed that the effect of testing time on PPI gain was significant $[F(2,21)=7.5$, $p<.01]$. Bonferroni post hoc tests showed that the difference in PPI gain was significant between preconditioning and postconditioning testing $(p<.01)$ and between preconditioning and postextinction testing $(p<.05)$, but not between postconditioning and postextinction testing, $(p>.05)$.

Other one-way ANOVAs showed that the effect of testing time on PPI gain was not significant for socially reared rats with the conditioning control manipulation $(p>.05)$, isolation-reared rats with the fear conditioning manipulation $(p>.05)$, or isolation-reared rats with the conditioning control manipulation $(p>.05)$.

These results confirm that perceived spatial separation between the prepulse and masker enhanced PPI only in socially reared rats and only after the manipulation of fear conditioning had been conducted.

\section{DISCUSSION}

The results of this study are consistent with previous reports that fear conditioning of the prepulse enhances 
Precontrol

Postcontrol

Socially Reared
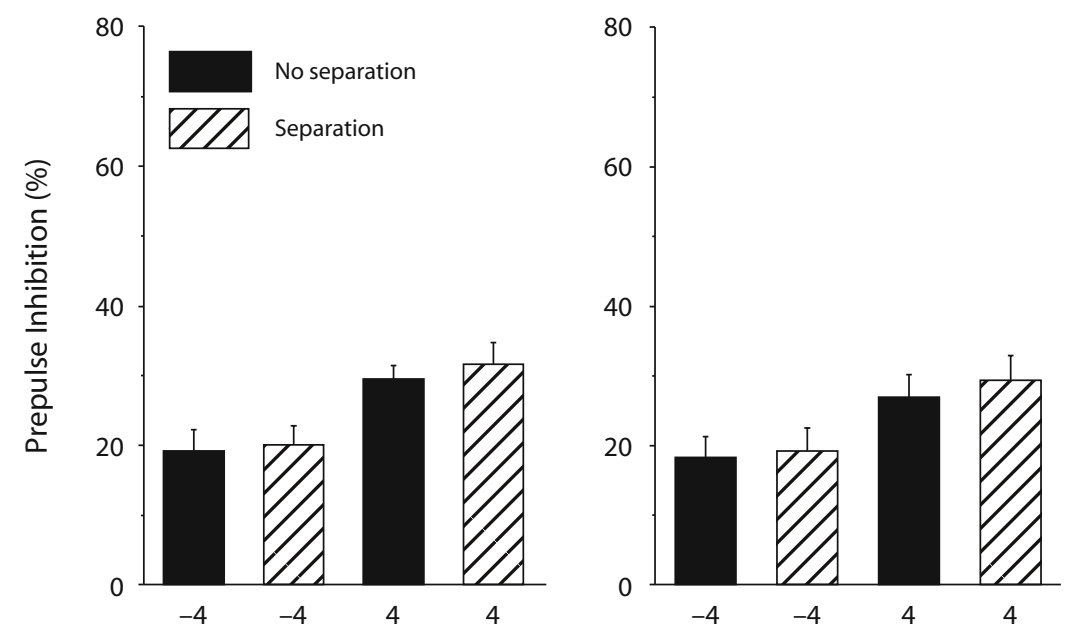

Isolation Reared
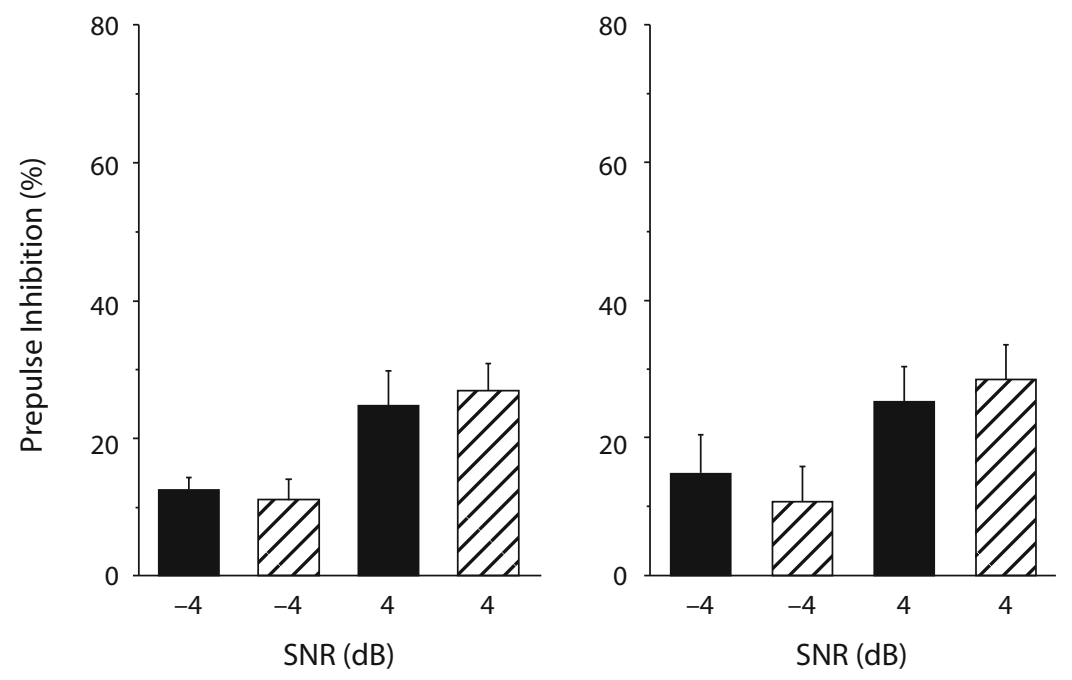

Figure 6. Prepulse inhibition (PPI) under noise-masking conditions before and after the manipulation of conditioning control, when the signal-to-noise ratio (SNR) was either -4 or $+4 \mathrm{~dB}$ and the prepulse and masker were either perceptually separated (diagonal bars) or perceptually colocated (black bars) for the two subgroups receiving the manipulation of conditioning control. Note that perceived spatial separation had no effect on PPI either before or after the manipulation of conditioning control in both socially reared rats and isolation-reared rats. Error bars represent the standard errors of the means.

PPI in normal rats (J. Huang et al., 2007; N. X. Li et al., 2008; Zou et al., 2007) and that isolation rearing impairs both PPI (Cilia et al., 2005; N. X. Li et al., 2008; van den Buuse et al., 2003) and the fear-conditioning-induced PPI enhancement (N. X. Li et al., 2008). Moreover, the results of this study, for the first time, show that perceived spatial separation between the fear-conditioned prepulse and noise masker, which was induced by the precedence effect, further enhanced PPI in socially reared rats, but not in isolation-reared rats.
Following fear conditioning, PPI enhancement and startle enhancement were not correlated. First, in socially reared rats, both the manipulation of fear conditioning and the manipulation of conditioning control enhanced the baseline startle, but only fear conditioning enhanced PPI. Also, in socially reared rats with fear conditioning, the conditioning manipulation enhanced the baseline startle but decreased the amplitude of the prepulse-inhibited startle response, indicating that the increase of PPI cannot be explained by the enhancement of baseline startle. 
Socially Reared

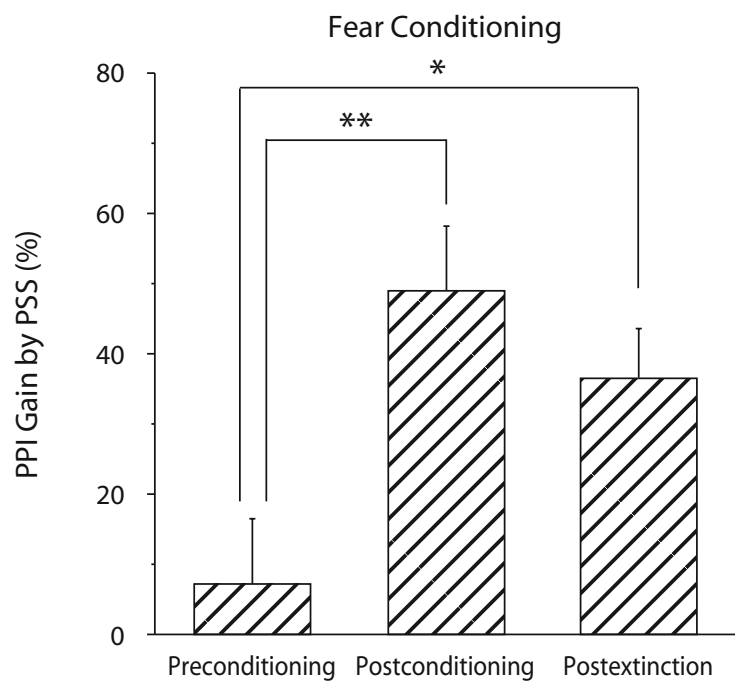

Conditioning Control

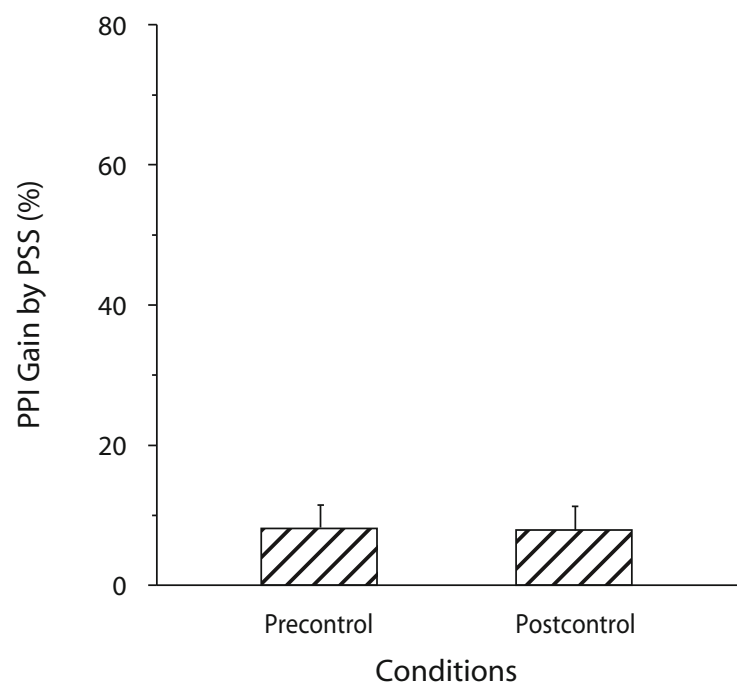

Isolation Reared

Fear Conditioning

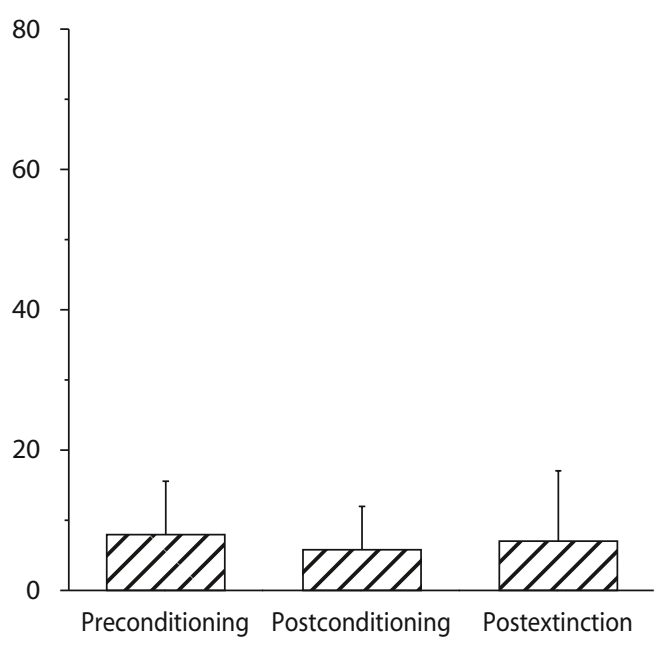

Conditioning Control

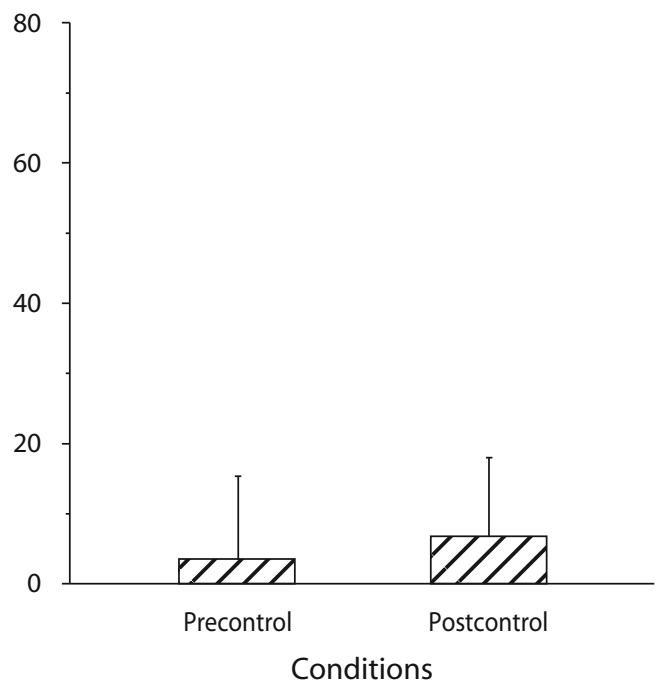

Figure 7. Prepulse inhibition (PPI) gains induced by perceived spatial separation before and after manipulations for each of the four subgroups. Note that the PPI gain induced by perceived spatial separation occurred after, but not before, the manipulation of fear conditioning in socially reared rats, but not in isolation-reared rats. The PPI gain was smaller but still significant after the extinction manipulation. The manipulation of conditioning control did not cause significant PPI gains. Error bars represent the standard errors of the means. PSS: perceived spatial separation between the prepulse and the noise masker. ${ }^{*} p<.05$. ${ }^{* *} p<.01$, by one-way ANOVA and Bonferroni post hoc tests.

Moreover, the extinction manipulation in socially reared rats with fear conditioning reduced the baseline startle but did not affect the PPI gain caused by perceived spatial separation. Finally, in isolation-reared rats, the baseline startle, but not PPI, was significantly altered by either the manipulation of fear conditioning or the manipulation of conditioning control.

It has been known that the amplitude of the acoustic startle reflex is enhanced when a stimulus previously paired with footshock is presented before the startling stimulus (e.g., Brown, Kalish, \& Farber, 1951; Davis, Schlesinger,
\& Sorenson, 1989). However, this conditioned fear potentiation of startle depends largely on the interval between the CS and the startling stimulus. For example, the Davis et al. study (see their Figure 7) showed that when the onset delay between the CS (fluorescent light) and the startling noise was 25 or $50 \mathrm{msec}$, the CS caused an enhanced inhibition of the startle reflex; when the onset delay became longer than $200 \mathrm{msec}$, the CS caused an enhancement of the startle reflex. Nevertheless, neither the present study nor our previous studies (J. Huang et al., 2007; N. X. Li et al., 2008; Zou et al., 2007) have shown any enhancing 
effects of the conditioned acoustic prepulse on startle, suggesting that the PPI-enhancing effect of the conditioned prepulse overpowered any potential startle-enhancing effect of the conditioned prepulse under the experimental conditions used in our studies. Note that there are several important differences between the Davis et al. study and our studies, including the difference in prepulse modality (light stimulus vs. acoustic stimulus) and the differences in conditioning procedure (e.g., 500-msec footshock duration vs. 3-msec footshock duration). Particularly, the onset intervals between the prepulse and startling noise used in our studies were restricted to the range in which marked PPI is induced (less than $210 \mathrm{msec}$ ). To further confirm the enhancing effect of a conditioned acoustic prepulse on rats' PPI when neither the prepulse energy level nor the masker energy level is substantially changed, the present study for the first time examined whether the precedenceeffect-induced perceptual separation between the prepulse and noise masker enhances PPI.

In humans, the precedence-effect-induced perceived spatial separation between target speech and masker facilitates selective attention to the signal stream and improves recognition of target speech (e.g., Freyman et al., 1999; Y. Huang et al., 2008; L. Li et al., 2004; Rakerd et al., 2006; Wu et al., 2005). Moreover, the unmasking effect of perceived spatial separation depends on the masker type. When the masker is steady state speech spectrum noise, which induces energetic masking of target speech, the perceived spatial separation produces a smaller (but significant) release of target speech from masking (Freyman et al., 1999; L. Li et al., 2004; Wu et al., 2005; for the concept of energetic masking, see a recent review by Schneider, Li, \& Daneman, 2007). When the masker is disruptive speech, which induces both energetic and informational masking of target speech, the perceived spatial separation produces a marked release of target speech from masking (Freyman et al., 1999; L. Li et al., 2004; $\mathrm{Wu}$ et al., 2005; for the concept of informational masking, see the review by Schneider et al., 2007). Thus, perceived spatial separation between the signal and masker, which does not substantially change the SNR at the listener's ear, reduces both informational masking and energetic masking with different extents. It is of interest to know whether, in rats, the effect of perceived separation on PPI becomes even larger when the background masker is informational.

It should be noted that any perceptual cues, as long as they facilitate selective attention to the target, can release the signal from masking. For example, familiarity with part of the content of target speech significantly releases target speech from either noise masking or speech masking, but the release from speech masking is substantially larger than that from noise masking (Freyman, Balakrishnan, \& Helfer, 2004; Yang et al., 2007). Thus, there is still plenty of space for developing new rat models for studying the effects of selective attention to the prepulse on PPI in the laboratory animal species.

As was mentioned in the introduction, either perceptual processing of, or selective attention to, the prepulse enhances PPI in mentally healthy people (Bradley et al.,
2006; Bradley et al., 1993; Filion \& Poje, 2003; Grillon \& Davis, 1997; Heekeren et al., 2004; Schell et al., 2000; Thorne et al., 2005). Previous studies have shown that rats are able to detect a correlation change between sounds delivered from two spatially separated locations (J. Huang et al., 2007) and experience the perceptual fusion of two correlated sounds delivered from spatially separated locations (e.g., Hoeffding \& Harrison, 1979; Kelly, 1974). The present study has shown that in socially reared rats, introducing a difference in the interloudspeaker delay between the fear-conditioned prepulse and the masking noise significantly enhanced PPI, supporting the view that the precedence effect can occur in rats. Thus, rats may be able to use the perceptual segregation between prepulse and masker images to improve detection/perception of the conditioned prepulse, leading to enhanced PPI. In other words, rats may have the ability to unmask target signals in noisy, reverberant environments by perceptually integrating correlated sound waves. In this study, random pairing of the prepulse with footshock did not enhance PPI. This result suggests that if the prepulse was not fear conditioned, due to the lack of ecological value of the prepulse, it was not selectively attended by rats during the presentation of the noise masker, even though perceived spatial separation between the prepulse and the masker could be experienced in rats across all the subgroups. Thus, the top-down regulating process must be essential for causing a marked effect of perceived spatial separation on PPI.

Also as was mentioned in the introduction, PPI protects the early process of the prepulse stimulus from interference by extraneous stimuli. The results of this study further confirm the tight relationship between sensory gating and perceptual processing and may be useful for improving animal models of schizophrenia. Impaired attentional modulation of PPI has been found in schizophrenic patients and schizotypal personality disordered subjects (Dawson et al., 1993; Hazlett et al., 2003; Hazlett et al., 2007), and schizophrenic patients are more vulnerable to both forward masking and backward masking with noise (Kallstrand et al., 2002). Thus, an important issue is whether the conditional modulation and/or perceptual modulation of PPI is useful for improving animal models for studying schizophrenia. Clearly, further neurophysiological, neuroanatomical, and neuropharmacological approaches are needed to combine with the PPI modulation model established in this study.

It has been known that, in rats, isolation rearing results in various schizophrenic-like cognitive/behavioral abnormalities, including spontaneous hyperactivity in open-field environments, recognition memory deficits, reduced PPI, deficits in attentional set-shifting performance (impaired inhibitory control in attentional selection), and impaired reversal learning in the rotating T-maze (e.g., Arakawa, 2005; Bianchi et al., 2006; Cilia et al., 2005; Geyer, Wilkinson, Humby, \& Robbins, 1993; Jones, Marsden, \& Robbins, 1991; Lapiz, Mateo, \& Parker, 2000; N. X. Li et al., 2007; N. X. Li et al., 2008; McLean et al., in press; Paulus, Bakshi, \& Geyer, 1998; Reboucas \& Schmidek, 1997; Schrijver \& Würbel, 2001; van den Buuse et al., 
2003; Varty \& Geyer, 1998; Varty, Paulus, Braff, \& Geyer, 2000; Weiss, Domeney, Moreau, Russig, \& Feldon, 2001; Wilkinson et al., 1994; for a recent review, see Fone \& Porkess, 2008). Thus, an important issue is how these previously reported isolation-induced deficits are associated with the impairment of PPI enhancement induced by perceptual separation between a conditioned prepulse and noise masker in isolation-reared rats.

In the present study, as was mentioned in the Method section, when the signal and masking noise were copresented in a testing session, the onset of the noise presented from the left loudspeaker either led or lagged behind that from the right loudspeaker by $1 \mathrm{msec}$, leading to a single fused noise image being perceived at either the left or the right loudspeaker throughout the session. However, the leading loudspeaker for the prepulse presentation randomly changed between the two loudspeakers across trials in the session, leading to a single fused prepulse image whose perceived position randomly changed between the two loudspeakers across trials. In a testing session with the right loudspeaker as the leading loudspeaker for the noise presentation, for example, the salience of the prepulse image would be lower when the prepulse image was colocated with the noise image at the right loudspeaker, but higher when the prepulse image was perceived as being at the left loudspeaker. Thus, after the prepulse became fear conditioned (ecologically significant), the rat with social rearing would allocate more attentional resource to the position of the left loudspeaker with the more salient prepulse image in this testing session, thereby leading to higher PPI magnitude when the prepulse and noise were perceived as separated. In addition, since the noise image continuously occurred at the right loudspeaker in this testing session, the rat would need to inhibit the attentiondrawing influence of the noise image in order to maintain selective spatial attention to the prepulse image at the left loudspeaker. Due to the impairment of inhibitory control in attentional selection caused by isolation rearing (McLean et al., in press; Schrijver \& Würbel, 2001), isolation-reared rats might not be able to efficiently shift and/or maintain selective attention to the location with the more salient target image.

In rats, isolation rearing also results in substantial changes in neural structures/neurotransmissions (e.g., Barr et al., 2004; Dalley, Theobald, Pereira, Li, \& Robbins, 2002; Day-Wilson, Jones, Southam, Cilia, \& Totterdell, 2006; Harte et al., 2004; Heidbreder et al., 2001; Heidbreder et al., 2000; Jones, Hernandez, Kendall, Marsden, \& Robbins, 1992; Jones et al., 1991; Lapiz et al., 2000; Muchimapura, Mason, \& Marsden, 2003; Preece, Dalley, \& Theobald, 2004; Silva-Gomez, Rojas, Juarez, \& Flores, 2003; Whitaker-Azmitia, Zhou, Hobin, $\&$ Borella, 2000; for a recent review, see Fone \& Porkess, 2008). Particularly, it results in both structure abnormalities (Day-Wilson et al., 2006; Melendez, Gregory, Bardo, $\&$ Kalivas, 2004; Preece et al., 2004) and neurotransmitter abnormalities (involving serotonin, dopamine, and glutamate; Dalley et al., 2002; Heidbreder et al., 2001; Jones et al., 1992; Jones et al., 1991; Leng, Feldon, \& Ferger, 2004; Melendez et al., 2004) in the medial prefrontal cortex (mPFC). Functionally, the rat's mPFC is involved in attentional control (e.g., Wall \& Messier, 2001). Thus, in the isolation-reared rats used in this study, isolationrearing-caused mPFC abnormalities, which impaired the attentional-control function, would be directly associated with the lack of precedence-effect-induced PPI enhancement.

On the basis of postulation by Weinberger (1987), the prefrontal cortex, which is typically implicated in schizophrenia, reaches its anatomical and functional maturity only in early adulthood. If early neurological injuries in the prefrontal cortex occur before prefrontal maturity, the effects of the injuries may remain silent until the prefrontal cortex matures. This neurodevelopmental hypothesis of schizophrenia emphasizes that certain early-life environmental factors can have substantial influence upon processes of prefrontal maturation. Thus, whether isolationinduced damage to the prefrontal cortex causes the lack of the effect of perceived separation on PPI in isolationreared rats will be an important issue in future studies.

Moreover, studies using functional magnetic resonance imaging have suggested that abnormalities in functional connections between the mPFC and parietal cortex are involved in schizophrenia (e.g., Callicott et al., 1998; Tan et al., 2006). In Mongolian gerbils, isolation rearing reduces the axonal projections from the $\mathrm{mPFC}$ to the parietal cortex (Bagorda, Teuchert-Noodt, \& Lehmann, 2006). It has been known that the parietal cortex in humans is involved in the modulation of spatial attention by fear-conditioned stimuli (Armony \& Dolan, 2002), and the parietal cortex in rats is involved in maintaining selective attention to signals (Broussard, Sarter, \& Givens, 2006; Corwin \& Reep, 1998). Although it is still unclear whether isolation rearing in rats causes dysconnection between the mPFC and the parietal cortex, and even neural damage to the parietal cortex, in future studies it will be important to address whether multimodal parietal regions of rats, such as the posterior parietal cortex, contribute to the precedence-effect-induced enhancement of PPI.

The results of this study also show that after the extinction manipulation, PPI decreased to the preconditioning level when the noise masker was not presented, but the PPI enhancement induced by perceived spatial separation under noise masking was still significant in socially reared rats. This resistance of PPI enhancement induced by perceived spatial separation to the extinction manipulation suggests that separation-induced PPI enhancement and fear-conditioning-induced PPI enhancement do not share the same underlying mechanisms. Thus, isolation rearing may cause impairments of PPI modulations at different cognitive levels, and these impairments of PPI modulations may be useful for advancing the animal model for studying the biological and developmental mechanisms underlying schizophrenia.

\section{AUTHOR NOTE}

This work was supported by the National Natural Science Foundation of China (Grants 30711120563, 30670704, 60605016, 60535030, and 60435010), the National High Technology Research and Development Program of China (Grants 2006AA01Z196 and 2006AA010103), 
the Trans-Century Training Program Foundation for the Talents by the State Education Commission, and "985" grants from Peking University. Correspondence concerning this article should be addressed to L. Li, Department of Psychology, Peking University, Beijing 100871, China (e-mail: liangli@pku.edu.cn).

\section{REFERENCES}

ARAKaWA, H. (2005). Interaction between isolation rearing and social development on exploratory behavior in male rats. Behavior Processes, 70, 223-234.

Armony, J. L., \& Dolan, R. J. (2002). Modulation of spatial attention by fear-conditioned stimuli: An event-related fMRI study. Neuropsychologia, 40, 817-826.

Bagorda, F., Teuchert-Noodt, G., \& Lehmann, K. (2006). Isolation rearing or methamphetamine traumatization induce a "dysconnection" of prefrontal efferents in gerbils: Implications for schizophrenia. Journal of Neural Transmission, 113, 365-379.

Barr, A. M., Young, C. E., Sawada, K., Trimble, W. S., Phillips, A. G., \& Honer, W. G. (2004). Abnormalities of presynaptic protein CDCrel-1 in striatum of rats reared in social isolation: Relevance to neural connectivity in schizophrenia. European Journal of Neuroscience, 20, 303-307.

Barsz, K., Ison, J. R., Snell, K. B., \& Walton, J. P. (2002). Behavioral and neural measures of auditory temporal acuity in aging humans and mice. Neurobiology of Aging, 23, 565-578.

Bianchi, M., Fone, K. F. C., Azmi, N., Heidbreder, C. A., Hagan, J. J., \& MARsDEN, C. A. (2006). Isolation rearing induces recognition memory deficits accompanied by cytoskeletal alterations in rat hippocampus. European Journal of Neuroscience, 24, 2894-2902.

Blauert, J. (1997). Spatial hearing. Cambridge, MA: MIT Press.

Bradley, M. M., Codispoti, M., \& Lang, P. J. (2006). A multiprocess account of startle modulation during affective perception. Psychophysiology, 43, 486-497.

Bradley, M. M., Cuthbert, B. N., \& Lang, P. J. (1993). Pictures as prepulse: Attention and emotion in startle modification. Psychophysiology, 30, 541-545.

Braff, D. L., Geyer, M. A., \& Swerdlow, N. R. (2001). Human studies of prepulse inhibition of startle: Normal subjects, patient groups, and pharmacological studies. Psychopharmacology, 156, 234-238.

Braff, D. L., Stone, C., Callaway, E., Geyer, M. A., Glick, I., \& BALI, L. (1978). Prestimulus effects on human startle reflex in normals and schizophrenics. Psychophysiology, 15, 339-343.

Braff, D. L., Swerdlow, N. R., \& Geyer, M. A. (1999). Symptom correlates of prepulse inhibition deficits in male schizophrenic patients. American Journal of Psychiatry, 156, 596-602.

Broussard, J., SARTER, M., \& Givens, B. (2006). Neuronal correlates of signal detection in the posterior parietal cortex of rats performing a sustained attention task. Neuroscience, 143, 407-417.

Brown, J. S., Kalish, H. I., \& Farber, I. E. (1951). Conditioned fear as revealed by magnitude of startle response to an auditory stimulus. Journal of Experimental Psychology, 41, 317-328.

Buckland, G., Buckland, J., Jamieson, C., \& Ison, J. R. (1969). Inhibition of startle response to acoustic stimulation produced by visual prestimulation. Journal of Comparative \& Physiological Psychology, 67, 493-496.

Callicott, J. H., Ramsey, N. F., Tallent, K., Bertolino, A., Knable, M. B., Coppola, R., ET AL. (1998). Functional magnetic resonance imaging brain mapping in psychiatry: Methodological issues illustrated in a study of working memory in schizophrenia. Neuropsychopharmacology, 18, 186-196.

CARlson, S., \& Willott, J. F. (1996). The behavioral salience of tones as indicated by prepulse inhibition of the startle response: Relationship to hearing loss and central neural plasticity in C57BL/6J mice. Hearing Research, 99, 168-175.

Cilia, J., Hatcher, P. D., \& Reavill, C. (2005). Long-term evaluation of isolation-rearing induced prepulse inhibition deficits in rats: An update. Psychopharmacology, 180, 57-62.

CoRwin, J. V., \& ReeP, R. L. (1998). Rodent posterior parietal cortex as a component of a cortical network mediating directed spatial attention. Psychobiology, 26, 87-102.

Cranford, J. L., \& Oberholtzer, M. (1976). Role of neocortex in binaural hearing in the cat: II. Precedence effect in sound localization. Brain Research, 111, 225-239.

Dalley, J. W., Theobald, D. E., Pereira, E. A. C., Li, P. M. M. C., \& Robbins, T. W. (2002). Specific abnormalities in serotonin release in the prefrontal cortex of isolation-reared rats measured during behavioral performance of a task assessing visuospatial attention and impulsivity. Psychopharmacology, 164, 329-340.

Davis, M., Schlesinger, L. S., \& Sorenson, C. A. (1989). Temporal specificity of fear conditioning: Effects of different conditioned stimulus-unconditioned stimulus intervals on the fear-potentiated startle effect. Journal of Experimental Psychology: Animal Behavior Processes, 15, 295-310.

Dawson, M. E., Hazlett, E. A., Filion, D. L., Nuechterlein, K. H., \& SCHELl, A. M. (1993). Attention and schizophrenia: Impaired modulation of the startle reflex. Journal of Abnormal Psychology, 102, 633641 .

Dawson, M. E., Schell, A. M., Hazlett, E. A., Nuechterlein, K. H., \& FILION, D. L. (2000). On the clinical and cognitive meaning of impaired sensorimotor gating in schizophrenia. Psychiatry Research, 96, 187-197.

Day-Wilson, K. M., Jones, D. N. C., Southam, E., Cilia, J., \& TotTERDELL, S. (2006). Medial prefrontal cortex volume loss in rats with isolation rearing-induced deficits in prepulse inhibition of acoustic startle. Neuroscience, 141, 1113-1121.

Dent, M. L., \& Dooling, R. J. (2004). The precedence effect in three species of birds (Melopsittacus undulatus, Serinus canaria, and Taeniopygia guttata). Journal of Comparative Psychology, 118, 325-331.

Dent, M. L., Tollin, D. J., \& Yin, T. C. T. (2004). Cats exhibit the Franssen effect illusion. Journal of the Acoustical Society of America, 116, 3070-3074.

Du, Y., Huang, Q., Wu, X.-H., Galbraith, G. C., \& Li, L. (2007). Emotional-call-induced frequency-following responses in the rat's amygdala and inferior colliculus are unmasked by binaural interaction [online]. Society for Neuroscience Abstracts, No. 504.10/LL12.

Filion, D. L., \& PoJe, A. B. (2003). Selective and nonselective attention effects on prepulse inhibition of startle: A comparison of task and notask protocols. Biological Psychology, 64, 283-296.

Fone, K. C. F., \& Porkess, M. V. (2008). Behavioural and neurochemical effects of postweaning social isolation in rodents: Relevance to developmental neuropsychiatric disorders. Neuroscience \& Biobehavioral Reviews, 32, 1087-1102.

Freyman, R. L., Balakrishnan, U., \& Helfer, K. S. (2004). Effect of number of masking talkers and auditory priming on informational masking in speech recognition. Journal of the Acoustical Society of America, 115, 2246-2256.

Freyman, R. L., Helfer, K. S., McCall, D. D., \& Clifton, R. K. (1999). The role of perceived spatial separation in unmasking of speech. Journal of the Acoustical Society of America, 106, 3578-3588.

Geyer, M. A., Krebs-Thomson, K., BrafF, D. L., \& Swerdlow, N. R. (2001). Pharmacological studies of prepulse inhibition models of sensorimotor gating deficits in schizophrenia: A decade in review. Psychopharmacology, 156, 117-154.

Geyer, M. A., Wilkinson, L. S., Humby, T., \& Robbins, T. W. (1993). Isolation rearing of rats produces a deficit in prepulse inhibition of acoustic startle similar to that in schizophrenia. Biological Psychiatry, 34, 361-372.

Graham, F. K. (1975). The more or less startling effects of weak prestimulation. Psychophysiology, 12, 238-248.

GriLlon, C., \& Davis, M. (1997). Effects of stress and shock anticipation on prepulse inhibition of the startle reflex. Psychophysiology, 34, 511-517.

Harte, M. K., Powell, S. B., Reynolds, L. M., Swerdlow, N. R., Geyer, M. A., \& Reynolds, G. P. (2004). Reduced $N$-acetylaspartate in the temporal cortex of rats reared in isolation. Biological Psychiatry, 56, 296-299.

Hazlett, E. A., Levine, J., Buchsbaum, M. S., Silverman, J. M., New, A., Sevin, E. M., ET AL. (2003). Deficient attentional modulation of the startle response in patients with schizotypal personality disorder. American Journal of Psychiatry, 160, 1621-1626.

Hazlett, E. A., Romero, M. J., Haznedar, M. M., New, A. S., GoldStein, K. E., Newmark, R. E., et AL. (2007). Deficient attentional 
modulation of startle eyeblink is associated with symptom severity in the schizophrenia spectrum. Schizophrenia Research, 93, 288-295.

Heekeren, K., Meincke, U., Geyer, M. A., \& GouzoulisMAYFRANK, E. (2004). Attentional modulation of prepulse inhibition: A new startle paradigm. Neuropsychobiology, 49, 88-93.

Heidbreder, C. A., Foxton, R., Cilia, J., Hughes, Z. A., Shah, A. J., ATKINS, A., ET AL. (2001). Increased responsiveness of dopamine to atypical, but not typical antipsychotics in the medial prefrontal cortex of rats reared in isolation. Psychopharmacology, 156, 338-351.

Heidbreder, C. A., Weiss, I. C., Domeney, A. M., Pryce, C., Homber, J., Hedou, G., ET AL. (2000). Behavioral, neurochemical and endocrinological characterization of the early isolation syndrome. Neuroscience, 100, 749-768.

HoEfFding, V., \& Harrison, J. M. (1979). Auditory discrimination: Role of time and intensity in the precedence effect. Journal of the Experimental Analysis of Behavior, 32, 157-166.

HofFman, H. S., \& Ison, J. R. (1980). Reflex modification in the domain of startle: I. Some empirical findings and their implications for how the nervous system processes sensory input. Psychological Review, 87, 175-189.

HuAng, J., YANG, Z. G., Ping, J. L., LiU, X., WU, X. H., \& Li, L. (2007). The influence of the perceptual or fear learning on rats' prepulse inhibition induced by changes in the correlation between two spatially separated noise sounds. Hearing Research, 223, 1-10.

Huang, Y., Huang, Q., Chen, X., Qu, T.-S., Wu, X.-H., \& Li, L. (2008). Perceptual integration between target speech and target-speech reflection reduces masking for target-speech recognition in younger adults and older adults. Hearing Research, 244, 51-65.

Ison, J. R., Agrawal, P., PAK, J., \& Vaughn, W. J. (1998). Changes in temporal acuity with age and with hearing impairment in the mouse: A study of the acoustic startle reflex and its inhibition by brief decrements in noise level. Journal of the Acoustical Society of America, 104, 1696-1704.

Ison, J. R., \& Bowen, G. P. (2000). Scopolamine reduces sensitivity to auditory gaps in the rat, suggesting a cholinergic contribution to temporal acuity. Hearing Research, 145, 169-176.

Ison, J. R., \& HofFman, H. S. (1983). Reflex modification in the domain of startle: II. The anomalous history of a robust and ubiquitous phenomenon. Psychological Review, 94, 3-17.

Jones, G. H., Hernandez, T. D., Kendall, D. A., Marsden, C. A, \& Robbins, T. W. (1992). Dopaminergic and serotonergic function following isolation rearing in rats: Study of behavioural responses and postmortem and in vivo neurochemistry. Pharmacology, Biochemistry \& Behavior, 43, 17-35.

Jones, G. H., Marsden, C. A., \& Robbins, T. W. (1991). Behavioural rigidity and rule-learning deficits following isolation-rearing in the rat, neurochemical correlates. Behavioural Brain Research, 43, 35-50.

Jourdan, D., Ardid, D., Chapuy, E., Eschalier, A., \& Le Bars, D. (1995). Audible and ultrasonic vocalization elicited by single electrical nociceptive stimuli to the tail in the rat. Pain, 63, 237-249.

Kallstrand, J., Montnémery, P., Nielzn, S., \& Olsson, O. (2002). Auditory masking experiments in schizophrenia. Psychiatry Research, 113, 115-125.

KeLly, J. B. (1974). Localization of paired sound sources in the rat: Small time difference. Journal of the Acoustical Society of America, $\mathbf{5 5}, 1277-1284$.

Kumari, V., Soni, W., Mathew, V. M., \& Sharma, T. (2000). Prepulse inhibition of the startle response in men with schizophrenia: Effects of age of onset of illness, symptoms, and medication. Archives of General Psychiatry, 57, 609-614.

LAPIZ, M. D. S., MATEO, Y., \& PARKER, T. (2000). Effects of noradrenaline depletion in the brain on response to novelty in isolation-reared rats. Psychopharmacology, 152, 312-320.

Leitner, D. S., \& Girten, E. M. (1997). Dopamine receptor agonists alter gap prestimulus modulation. Psychopharmacology, 134, 213-220.

Leng, A., Feldon, J., \& Ferger, B. (2004). Long-term social isolation and medial prefrontal cortex: Dopaminergic and cholinergic neurotransmission. Pharmacology, Biochemistry \& Behavior, 77, 371-379.

Li, L., Daneman, M., QI, J. G., \& Schneider, B. A. (2004). Does the information content of an irrelevant source differentially affect speech recognition in younger and older adults? Journal of Experimental Psychology: Human Perception \& Performance, 30, 1077-1091.

Li, L., Korngut, L. M., Frost, B. J., \& Beninger, R. J. (1998). Prepulse inhibition following lesions of the inferior colliculus: Prepulse intensity functions. Physiology \& Behavior, 65, 133-139.

Li, L., QI, J. G., He, Y., Alain, C., \& Schneider, B. (2005). Attribute capture in the precedence effect for long-duration noise sounds. Hearing Research, 202, 235-247.

LI, L., \& YUE, Q. (2002). Auditory gating processes and binaural inhibition in the inferior colliculus. Hearing Research, 168, 113-124.

Li, N. X., Ping, J. L., Wu, R. B., WANG, C., Wu, X. H., \& Li, L. (2008). Auditory fear conditioning modulates prepulse inhibition in sociallyreared rats and isolation-reared rats. Behavioral Neuroscience, 122, $107-118$.

LI, N. X., Wu, X. H., \& LI, L. (2007). Chronic administration of clozapine alleviates reversal-learning impairment in isolation-reared rats. Behavioural Pharmacology, 18, 135-145.

Litovsky, R. Y., Colburn, H. S., Yost, W. A., \& Guzman, S. J. (1999). The precedence effect. Journal of the Acoustical Society of America, 106, 1633-1654.

Marsh, J. T., Worden, F. G., \& Smith, J. C. (1970). Auditory frequency following responses: Neural or artifact? Science, 169, 1222-1223.

McGrath, J. J., Feron, F. P., Burne, T. H. J., Mackay-Sim, A., \& EYLES, D. W. (2003). The neurodevelopmental hypothesis of schizophrenia: A review of recent developments. Annals of Medicine, 35, 86-93.

Mclean, S. L., Grayson, B., Harris, M., Protheroe, C., Bate, S., Woolley, M. L., \& NeIll, J. C. (in press). Isolation rearing impairs novel object recognition and attentional set shifting performance in female rats. Journal of Psychopharmacology.

Melendez, R. I., Gregory, M. L., Bardo, M. T., \& Kalivas, P. W. (2004). Impoverished rearing environment alters metabotrophic glutamate receptor expression and function in the prefrontal cortex. Neuropsychopharmacology, 29, 1980-1987.

Meyer, U., Feldon, J., Schedlowskib, M., \& Yee, B. K. (2005). Toward an immuno-precipitated neurodevelopmental animal model of schizophrenia. Neuroscience \& Biobehavioral Review, 29, 913-947.

Muchimapura, S., Mason, R., \& Marsden, C. A. (2003). Effect of isolation rearing on pre- and postsynaptic serotonergic function in the rat dorsal hippocampus. Synapse, 47, 209-217.

Paulus, M. P., BaKshi, V. P., \& Geyer, M. A. (1998). Isolation rearing affects sequential organization of motor behavior in postpubertal but not pre-pubertal Lister and Sprague-Dawley rats. Behavioural Brain Research, 94, 271-280.

Pickney, L. A. (1976). Inhibition of the startle in the rat by prior tactile stimulation. Animal Learning \& Behavior, 4, 467-472.

Preece, M. A., Dalley, J. W., \& Theobald, D. H. (2004). Region specific changes in forebrain 5-hydroxytryptamine(1A) and 5-hydroxytryptamine(2A) receptors in isolation-reared rats: An in vitro autoradiography study. Neuroscience, 123, 725-732.

Rakerd, B., Aaronson, N. L., \& Hartmann, W. M. (2006). Release from speech-on-speech masking by adding a delayed masker at a different location. Journal of the Acoustical Society of America, 119, 1597-1605.

Reboucas, R. C. R., \& SchmideK, W. R. (1997). Handing and isolation in three strains of rats affect open field, exploration, hoarding and predation. Physiology \& Behavior, 62, 1159-1164.

RösKaM, S., \& КосH, M. (2006). Enhanced prepulse inhibition of startle using salient prepulses in rats. International Journal of Psychophysiology, 60, 10-14.

Schell, A. M., Wynn, J. K., Dawson, M. E., SinaiI, N., \& Niebala, C. B. (2000). Automatic and controlled attentional processes in startle eyeblink modification: Effects of habituation of the prepulse. Psychophysiology, 37, 409-417.

Schneider, B. A., Li, L., \& Daneman, M. (2007). How noise interferes with speech comprehension in everyday listening situations. Journal of the American Academy of Audiology, 18, 559-572.

SCHRIJVER, N. C., \& WürBEL, H. (2001). Early social deprivation disrupts attentional, but not affective, shifts in rats. Behavioral Neuroscience, 115, 437-442.

Sikes, R. W., \& Vogt, B. A. (1992). Nociceptive neurons in area 24 of rabbit cingulate cortex. Journal of Neurophysiololgy, 68, 1720-1732. 
Silva-Gomez, A., Rojas, D., Juarez, I., \& Flores, G. (2003). Decreased dendritic spine density on prefrontal cortical and hippocampal pyramidal neurons in postweaning social isolation rats. Brain Research, 983, 128-136.

Spitzer, M. W., \& TAKahashi, T. T. (2006). Sound localization by barn owls in a simulated echoic environment. Journal of Neurophysiology, 95, 3571-3584.

Swerdlow, N. R., Light, G. A., Cadenhead, K. S., Sprock, J., Hsieh, M. H., \& BRAFF, D. L. (2006). Startle gating deficits in a large cohort of patients with schizophrenia: Relationship to medications, symptoms, neurocognition, and level of function. Archives of General Psychiatry, 63, 1325-1335.

Tan, H. Y., Sust, S., Buckholtz, J. W., Mattay, V. S., MeyerLindenberg, A., Egan, M. F., ET AL. (2006). Dysfunctional prefrontal regional specialization and compensation in schizophrenia. American Journal of Psychiatry, 163, 1969-1977.

Thorne, G. L., Dawsona, M. E., \& Schell, A. M. (2005). Attention and prepulse inhibition: The effects of task-relevant, irrelevant, and no-task conditions. International Journal of Psychophysiology, 56, 121-128.

Turner, J. G., Brozoski, T. J., Bauer, C. A., Parrish, J. L., \& Myers, K. (2006). Gap detection deficits in rats with tinnitus: A potential novel screening tool. Behavioral Neuroscience, 120, 188-195.

van den Buuse, M., Garner, B., \& Кoch, M. (2003). Neurodevelopmental animal models of schizophrenia: Effects on prepulse inhibition. Current Molecular Medicine, 3, 459-471.

Varty, G. B., \& Geyer, M. A. (1998). Effects of isolation rearing on startle reactivity, habituation, and prepulse inhibition in male Lewis, Sprague-Dawley, and Fischer F344 rats. Behavioral Neuroscience, 112, 1450-1457.

Varty, G. B., Paulus, M. P., Braff, D. L., \& Geyer, M. A. (2000). Environmental enrichment and isolation rearing in the rat: Effects on locomotor behavior and startle response plasticity. Biological Psychiatry, 47, 864-873.

Villanueva, L., Bing, Z., Bouhassira, D., \& Le Bars, D. (1989). Encoding of electrical, thermal, and mechanical noxious stimuli by subnucleus reticularis dorsalis neurons in the rat medulla. Journal of Neurophysiology, 61, 391-402.

Wall, P. M., \& Messier, C. (2001). The hippocampal formation- orbitomedial prefrontal cortex circuit in the attentional control of active memory. Behavioural Brain Research, 127, 99-117.

Wallach, H., Newman, E. B., \& Rosenzweig, M. R. (1949). The precedence effect in sound localization. Journal of the Acoustical Society of America, 62, 315-336.

Weinberger, D. R. (1987). Implications of normal brain-development for the pathogenesis of schizophrenia. Archives of General Psychiatry, 44, 660-669.

Weiss, I. C., Domeney, A. M., Moreau, J., Russig, H., \& Feldon, J. (2001). Dissociation between the effects of pre-weaning and/or postweaning social isolation on prepulse inhibition and latent inhibition in adult Sprague-Dawley rats. Behavioural Brain Research, 121, 207-218.

Weiss, I. C., \& Feldon, J. (2001). Environmental animal models for sensorimotor gating deficiencies in schizophrenia: A review. Psychopharmacology, 156, 305-326.

Whitaker-Azmitia, P., Zhou, F., Hobin, J., \& Borella, A. (2000). Isolation-fearing of rats produces deficits as adults in the serotonergic innervation of hippocampus. Peptides, 21, 1755-1759.

Wilkinson, L. S., Killcross, S. S., Humby, T., Hall, F. S., Geyer, M. A., \& Robbins, T. W. (1994). Social-isolation in the rat produces developmentally specific deficits in prepulse inhibition of the acoustic startle response without disturbing latent inhibition. Neuropsychopharmacology, 10, 61-72.

Wu, X. H., Wang, C., Chen, J., Qu, H. W., LI, W. R., Wu, Y. H., eT AL. (2005). The effect of perceived spatial separation on informational masking of Chinese speech. Hearing Research, 199, 1-10.

YANG, Z. G., Chen, J., Wu, X. H., Wu, Y. H., Schneider, B. A., \& Li, L. (2007). The effect of voice cuing on releasing Chinese speech from informational masking. Speech Communication, 49, 892-904.

YounG, J. S., \& FeCHTER, L. D. (1983). Reflex inhibition procedures for animal audiometry: A technique for assessing ototoxicity. Journal of the Acoustical Society of America, 73, 1686-1693.

Zou, D., Huang, J., Wu, X. H., \& LI, L. (2007). Metabotropic glutamate subtype 5 receptors modulate fear-conditioning induced enhancement of prepulse inhibition in rats. Neuropharmacology, 52, 476-486.

(Manuscript received September 16, 2008; revision accepted for publication October 31, 2008.) 